\title{
Who Follows the Generals? Polarization in Institutional Confidence in the Military
}

\author{
Michael A. Robinson* \\ Presented for the American Political Science (APSA) 2019 Annual Conference
}

September 3, 2019

\begin{abstract}
The military institution has enjoyed consistent and high levels of public confidence over the past several decades, making it one of the most respected entities in American society. However, this aggregate trend of high public confidence conceals an underlying polarization among partisans, who arrive at different conclusions over the institutional quality of the military. What explains the partisan divide in this evaluation process? This analysis argues that a failure of partisans to converge on a common understanding reflects a partisan bias resulting from (1) exposure to different information about the military and (2) different cognitive biases in using that information to render an opinion on institutional quality. Using observational data on news media reporting patterns and original text-as-data processed through unsupervised machine learning techniques, I find that partisans during a key phase of the Iraq War were exposed to widely different levels and frames of information on military performance. While Democrats were more likely to receive information on battlefield failures or organizational scandals, Republicans were less likely to observe news critical of the military. Furthermore, I find through original survey experimentation that even when presented with information on negative performance by the military, partisans adopt very different sensibilities in how that information is used to evaluate it. While Democrats and Independents clearly punish the institution for poor conduct, Republicans adopt an in-group defensiveness in line with previous study on co-partisan affective polarization. The implications of such subjective thinking on the military will present significant challenges to civil-military relations into the future.
\end{abstract}

\footnotetext{
* Michael A. Robinson is an assistant professor of international affairs at the United States Military Academy at West Point. This project was made possible through generous funding and from the Lab for the Study of American Values (LSAV). I would also like to thank Adam Bonica, Jonathan Chu, Mark Jacobsen, Scott Sagan, Kori Schake, Kenneth Schultz, Paul Sniderman, Mike Tomz, Amy Zegart, and audience members at the Naval Post-Graduate School and Stanford Security Studies Working Group (SSWG). Stanford IRB Protocol \#40724.
} 
Considerable theoretical effort has been made in articulating the ways in which attributes of information sources such as knowledge, trustworthiness, and like-mindedness (Downs 1957; Zaller 1992 Lupia and McCubbins 1998) can scale the persuasiveness of their messages. Public confidence in political and social institutions is an essential part of a functioning democracy, not only as a reflection of popular approval of institutional performance, but as an expression of the reliability of information that come from these institutions. In an environment where the value and veracity of political information are increasingly characterized by "echo-chamber" media exposure (Iyengar and Hahn 2009; Jamieson and Cappella 2008, Stroud 2008), the process by which individuals seek credible elite voices and form policy preferences is significant. However, while study of this dynamic has traditionally focused on political institutions with low historical levels of public confidence, this analysis directs attention to one with unique functional imperatives and high public trust: the military

The broad trend of declining confidence in a variety of political and social institutions has been met with renewed debate over the process by which individuals decide to express trust in them and the implications this trend has for the long-term viability of democratic values (Nye 1997 Pharr, Putnam, and Dalton 2000). Given the increasingly central role that active and retired military elites play in policy formation, governance, media commentary, and business, scholars have devoted more attention to the potential influence of this elite bloc. The capacity of military officials to shape public opinion on policy (Post and Sechser 2016), influence public support for military intervention (Golby, Feaver, and Dropp 2017), inform the public's perception of success probability during war (Sidman and Norpoth 2012), or grant credibility through endorsement relies on the military institution's considerable clout with the public. High levels of support for the military also come during a time where a sizable portion of U.S. society admits mixed understanding of the military (Schake and Mattis 2016) and increased acceptance of authoritarian measures in government (Foa and Mounk 2016).

Despite the comparably high public confidence the institution enjoys relative to others in society, pooled data of expressed public trust in the military can be misleading. The institutional trust literature is largely devoid of dedicated study on public attitudes toward the military, while those that approach the subject focus on high aggregate levels of confidence captured in most polls (Gronke and Feaver 2001; Hill, Wong, and Gerras 2013). These studies overlook increasing polarization in assessing military credibility within the civilian public itself (Liebert and Golby 2017). While the civil-military relations 
literature prescribes an apolitical military outside the realm of partisan politics, partisans in U.S. society exhibit widely divergent attitudes in assessing the credibility of the institution. Examination of the military in a partisan context yields the primary research question of this analysis: what explains partisan polarization in perceived credibility of the military?

The curious failure of partisans to converge on a common understanding of military institutional quality requires study for several reasons. First, an inability to objectively evaluate the credibility of select institutions in society contributes to a broader devaluation of fact-driven political discourse. A military institution that can maintain high levels of public confidence among certain partisans despite organizational scandals or frustrations on the battlefield could negatively influence the ability of individuals to properly learn the lessons of foreign policy failures (Schultz 2018). Second, as partisan sorting deepens political and social polarization, the capture of military confidence into a partisan identity has potentially damaging implications for the preservation of civil-military norms. While democracy and civil-military scholars argue that a military institution removed from partisan political fights is necessary for the preservation of democratic values, the perception of partisan "capture" of the military institution could be damaging to the integrity of the armed forces and of the very credibility it carries with the public (Golby, Feaver, and Dropp 2017; Dempsey 2009; Kohn 2002).

While patterns of confidence in the military are unique for several reasons, one of its more puzzling characteristics is a pronounced divergence in partisan attitudes despite the military's apolitical mandate and non-partisan professional norms. Seemingly out-sized support among conservatives has been explained in the past as the result of partisan realignment (Huntington 1957; Desch 2001), defense policy preferences (Kohn 1994), and shifting post-conscription military demography (Desch 2001). However, while I believe that these help to explain the static existence of a baseline partisan "confidence gap", I argue that a complete accounting of this widening divide requires viewing expressed trust as a dynamic process. Because of the necessity of new information in evaluative processing when judging the credibility of an institution like the military, I argue that the confidence gap between partisans is not simply the result of different preferences, but of divergent pathologies in how partisans receive and employ updating information.

My analysis proceeds as follows: first, I briefly discuss the nature of this growing trend of polar- 
ization in assessment of the military institution. The principal aim of this section is to demonstrate the partisan separation on evaluation of the military institution and to review existing explanations for this divide. Second, I propose a complementary theory for the partisan confidence gap that contributes to the existing body of work by (1) considering the impact of selective information exposure and (2) incorporating the influence of affective polarization on impressions about military credibility. As such, I argue that both selective exposure to information and biased updating can help to better explain polarization in military trust. Third, I assess the validity of these two explanations incorporating original text data, observational data on media reporting habits, and original survey experimentation designed to test individual attitudes on trust for the military institution. I conclude by discussing the potential implications of such patterns on the quality of civil-military relations and the objective evaluation of US foreign policy by the public.

\section{The Partisan Gap in Military Credibility}

Polarized attitudes on the credibility of elite voices has significant implications when considering how the public forms attitudes on important policy decisions. As previously noted, the credibility of cue sources to the individual is an irreducible factor in the persuasiveness of that source and its message. In forming preferences on complex issues, the individual makes cost-efficient choices in seeking out sources and allowing themselves to be persuaded by information advanced by credible actors. Specific articulations of what "credibility" entails vary; while usually requiring some baseline of knowledge about the subject under debate, different theoretical accounts of credibility include consideration of costly signaling (Baum and Groeling 2009), ideological "like-mindedness" (Downs 1957), elite status or unity (Zaller 1992), likability (Brady and Sniderman 1985), and "trustworthiness" in being able to reveal accurate information (Lupia and McCubbins 1998). Reliance on source attributes like credibility is more likely under circumstances where the respondent has minimal understanding of the issue or exists in a high-distraction information environment (Petty and Cacioppo 1986). As a result, an understanding of which elite communities carry the most weight in the public debate requires some measure of institutional credibility.

While operationalizing source credibility for political institutions like the legislature can be more easily proxied for by partisan identity or regularly-surveyed job approval metrics, it is difficult to mea- 
sure the same value for apolitical institutions without public pressure incentives or electoral demands. However, public trust and confidence in institutions is a widely-collected survey device that affords the opportunity to overcome this problem and operationalize perceived source credibility more directly. Though there is considerable theoretical debate over whether expressed public trust is transactional and a reflection of incumbent performance (Citrin 1974 Lipset and Schneider 1983) or a broader statement about satisfaction with the system of government (Miller 1974 Williams 1985), popular trust in institutions provides a metric for the perceived reliability of these elite communities in society. ${ }^{1}$ While individuals should theoretically converge on some common evaluation of institutional performance particularly for institutions without a partisan function - we will observe that the military evokes increasingly divided attitudes.

Many analyses probing the broader trends of military institutional credibility have been limited by two constraints. First, these studies have focused on pooled, aggregate, or cross-national statistics of public confidence, with incidental accounting of how the military institution fits into the public consciousness. However, some efforts have been made to disaggregate specific institutions from the whole in an effort to visualize underlying correlations between individual organizations. Some scholars have found that the military escapes classification as "the only public institution whose performance can be expected to operate and be evaluated according to standards different from those of civic life" (Newton and Norris 2000), while others place the military into the category of "order institutions" valued for their objective enforcement of the law (Rothstein and Stolle 2007). By what evaluative method individuals judge the military remains undetermined even by these efforts. The second limitation is that the public is often envisioned as a political whole. This tendency can be misleading, projecting an image of broad consensus on a dynamic that exhibits many of the same aspects of polarization we observe in other realms of public opinion. ${ }^{2}$ Whereas many studies have focused on the high level of public confidence the military enjoys, failing to examine this trend among political subgroups has prevented more nuanced study.

\footnotetext{
${ }^{1}$ While the wording of various survey questions phrases these concepts differently, I use the terms trust and confidence interchangeably insofar as they speak to the individual's chosen criterion for positive performance.

${ }^{2}$ Regression analysis of the individual-level data from the primary institutional confidence surveys reveals the partisan asymmetry at the core of our research question. Linear probability regression models with year fixed-effects using the Gallup and GSS time-series datasets indicate that identification as a Republican emerges as the strongest predictor of high confidence in the military, even in fully-specified models controlling for education, race, gender, age cohort, and an indicator for whether a political co-partisan was the commander-in-chief at the time. Classification as 'high confidence' captures response to the confidence question with "a great deal/quite a lot" rendered as a binary variable; similarly the dependent variable in the GSS models was the top response of expressed confidence on that survey's three-point scale. Using a similar model with the most recent World Values Survey (WVS) data on US attitudes from 2011, I again observe that Republican vote-intent is a statistically significant predictor; additionally, high military confidence was positively shaped by preference for authoritarian political solutions, national pride, and concerns over terrorism, characteristics commonly associated with political conservatism (Hetherington and Suhay 2011).
} 
Table 1: Confidence Among Partisans for Select US Institutions (2017-18)

\begin{tabular}{|c|c|c|c|c|c|c|}
\hline & \multicolumn{3}{|c|}{ Gallup (2017) } & \multicolumn{3}{|c|}{ NPR/PBS/Marist (2018) } \\
\hline & Democrats & Republicans & Partisan Gap & Democrats & Republicans & Partisan Gap \\
\hline \multicolumn{7}{|l|}{ High Polarization } \\
\hline Presidency & $10 *$ & $60 *$ & $50 *$ & 7 & 37 & 30 \\
\hline Democratic Party & - & - & - & 26 & 3 & 23 \\
\hline Republican Party & - & - & - & 2 & 23 & 21 \\
\hline Military & $65 *$ & $83 *$ & $22 *$ & 44 & 65 & 21 \\
\hline Media/TV News & $31 *$ & $14 *$ & $17 *$ & 23 & 4 & 19 \\
\hline \multicolumn{7}{|l|}{ Low Polarization } \\
\hline Banking System & $30 *$ & $36 *$ & $6 *$ & 16 & 17 & 1 \\
\hline Small Business & $67 *$ & $73 *$ & $6 *$ & - & - & - \\
\hline Supreme Court & $43 *$ & $40 *$ & $3 *$ & 22 & 27 & 5 \\
\hline Congress & $11 *$ & $14 *$ & $3 *$ & 7 & 9 & 2 \\
\hline
\end{tabular}

NOTE: Reported figures depict levels of partisan confidence in select US institutions across both the Gallup Institutional Confidence survey (2017) and the NPR/PBS/Marist Poll (2018). Partisan Gap column indicates the magnitude (in percentage points) of difference between partisan subgroups on each institution surveyed. Asterisk $(*)$ indicates institutions where figures were computed using both "a great deal" and "quite a lot" of confidence combined due to data format. All other figures computed using highest ("a great deal") confidence response.

Challenging these prior limitations in the field of institutional confidence allows for observation of the primary empirical puzzle of this analysis: the partisan gap in military credibility. Table 1 reports Democratic and Republican levels of confidence for a variety of institutions in US society, including representative, power-checking, and order institutions. This figure captures not only the divide amongst partisans over the credibility of the military institution, but contextualizes this gap across other institutions in society. Partisan separation regarding the military rivals the same gap among other institutions that are highly susceptible to partisan calculations, such as the presidency and the media. Surprisingly, while we might expect evaluations of the military to resemble low-polarization institutions such as the courts or the banking system, this is not the case. Rather, partisans seem to be just as polarized about the military institution as they are about the major party establishments.

The notion that partisan calculations should inform impressions about the performance or institutional quality of the military is particularly curious given its apolitical mandate. The military institution has a specific role in society, to fight and win the nation's wars; however, despite the organization having no explicit partisan role, partisans arrive at different evaluations of the institution's credibility. What explains this divergence? Existing scholarship would suggest that elite-level alignment on policy preferences or military demography could explain such an arrangement. However, these explanations cannot 
explain a dynamic sustainment - and expansion - of the partisan gap across different administrations and states of military performance. In the following section, I propose a corollary theory, that separation in perceived institutional credibility - particularly during wartime - between partisans is the product of the different processes by which these groups receive new information about the institution and form resulting evaluations.

\section{Theoretical Development}

\section{Extant Explanations}

Many security scholars have studied the importance of partisan identity as a salient consideration in civil-military relations, whether in the context of how civilians and the military divide on the use of force (Golby 2011; Feaver and Kohn 2001), the public's knowledge and perception of the military in society (Schake and Mattis 2016; Burbach 2019), or the political demography of the military itself (Dempsey 2009. Urben 2010 Desch 2001). However, while these analyses describe elite-level dynamics or the political identification of the military, they speak less to the polarization that exists between subsets of that public in evaluating the credibility of an institution they commonly observe. Indeed, a conservative Republican preference for the military institution has been a persistent trend for several decades and one addressed laterally in broader discussions of civil-military relations in the United States. What explanations have been advanced that could explain, at least statically, the partisan "confidence gap" in the military institution?

At the elite level, closer proximity between the military and the Republican party has been attributed to a host of factors. The party's post-Vietnam role in loosening many of bureaucratic restrictions that the Kennedy and Johnson administrations had placed on the military led to a period of autonomy and expansive authorities in the Pentagon, developed further under the patronage of the Reagan-era buildup and the Goldwater-Nichols bureaucratic re-organization (Kohn 1994). The party leadership also seized on a critical opportunity to capture national security and patriotism as key aspects of the its post-war identity, filling the political void left by a Democratic party that retreated from interventionist rhetoric and favored domestic programs over expanded military funding. Indeed, even the military's image was better rehabilitated under Republican presidents, as William Odom states, that though "the Democrats have treated the military as the source of bad national strategy in Vietnam 
[...] the Republicans defended the military against the charge" (Kohn et al. 1994). This connection was deepened by increasingly aligned preferences for the use of force abroad (Golby 2011), militant internationalism (Wittkopf 1990), and increasing skepticism of more ideologically-distant Democratic leaders (Kohn 2002).

The rightward-changing demography of the military itself has also been a subject of study among civil-military scholars. Huntington (1957) early identified the emerging southern identity of the postconscription force, while the post-Vietnam all-volunteer military took on a far less representative profile than society at large. With the adoption of the "southern strategy" by Republicans in the 1960s and 1970s, Republicans leveraged their position as the national security party and its geographical inheritance of the American South to increase its electoral connections to servicemembers. Between 1976 and 1996, military officers had become far more outspoken in their identification with the party, increasing from $33 \%$ to $70 \%$, even though the larger society only increased identification with the party from $25 \%$ to $33 \%$ over the same period (Holsti 1998, Desch 2001). Political attitudes among military officers have swung decisively in favor of the Republican party, with those identifying as Democrats joining at lower rates and leaving at earlier times than Republican counterparts (Dempsey 2009). Recent survey evidence suggests that conservatives in the broader public find much more common political ground with the institutional values of the military as well. ${ }^{3}$

These efforts make a collectively compelling argument for explaining the existence of (1) a preference alignment on foreign policy between Republicans and the military at the elite level and (2) an increasing cultivation of military servicemembers as an extension of the party's constituency at the mass public level. However, this does not directly address why the conservative public would continue to imbue the military with high levels of seemingly unconditional trust, even amidst negative information shocks. As I will argue, the missing component is an understanding of how institutional confidence can be less an objective valuation of an organization's performance than it is itself an extension of partisan polarization and cognitive bias. With limited first-hand understanding of an institution, individuals are largely

\footnotetext{
${ }^{3}$ Schake and Mattis $(2016)$ find that $58 \%$ of Republicans believed military servicemembers to be "more socially conservative" than the rest of society, compared with $9 \%$ of Democrats who believed servicemembers were "less socially conservative" than the rest of society. Additionally, $72 \%$ of Republicans believed military values to be "about the same" or "less progressive" than the rest of society, compared with $16 \%$ of Democrats would believed military values were "more progressive". This speaks to the perception that Republicans feel military veterans are 'more like us' than Democrats or Independents. The survey finds that Republicans see the military as more meritocratic and that holding on to an "old-fashioned view of morality" is necessary for the institution. Compared to Democrats, Republicans are also more likely to believe that the military has "a great deal of respect for civilian society" and less likely to believe that civilian society possesses the same respect for the military in turn.
} 
dependent on other elites in society for information by which to form an opinion, such as the organized media (Nye 1997). However, media environments trafficked by different partisans may exhibit widely different sensibilities in their reporting patterns, making information unevenly available for use by the audience.

In the following section, I argue that we currently lack a dynamic understanding of partisan polarization in expressed trust for the military in a way that exceeds mere static explanations of preferences. Individuals with limited exposure to the military institution require third-party elite information to drive attitudes about its performance. Just as strong partisans are more likely to be politically active (Abramowitz and Saunders 2008), exhibit polarized attitudes (Iyengar and Hahn 2009), and downweight disconfirming information (Taber and Lodge 2006), they are also more likely to display increased ingroup bias (Mason 2015) and fail to objectively evaluate the quality of institutions (Iyengar, Sood, and Lelkes 2012). As such, I propose a theory linking how strong partisans acquire and use information about the military institution when making judgments about its credibility.

\section{A Dynamic Theory and the "Confidence Gap"}

The fundamental assertion of this analysis is that the confidence gap between partisans can be more completely explained by considering the methods by which individuals acquire and process new information about the military institution; if partisans on either side are more or less likely to acquire new and useful information, or biased in their interpretations of that information, then even poor performance or unethical activity by the military could prevent individuals in society from converging on some common assessment of the institution. Furthermore, any pattern of partisan polarization must include an account of the role of strong or ideologically "sorted" partisans in the process, as these individuals are both more relevant to the shaping of political discourse and are more likely to be driving polarization writ large (Mason 2015). Because of the strictly non-partisan and apolitical nature of the military, the existence of a bias-driven and partisan confidence gap could be symptomatic of shifting public attitudes about the appropriateness of a political role for the military.

However, why would partisans in society arrive at different expressed opinions about a non-partisan entity they both commonly observe? An incredibly rich literature in political science has focused on the varying processes by which individuals update their impressions of policies or institutions in response 
to new information. One theoretical school, advanced more recently by Achen (1992) and Gerber and Green (1999) contends that even partisan individuals are capable of rationally using new information to update their own prior beliefs. This conceptualization of fundamentally unbiased learning "holds that new information moves people with different partisan affinities (but similar levels of prior information) in the same direction and to approximately the same extent." When approval for a policy or leader across different partisan subgroups seems to track in a parallel fashion, they argue, this is clear evidence of unbiased learning.

However, Bartels (2002) argues against this interpretation; if a truly unbiased process were at work, partisan subgroups should not be moving in parallel, but converge on some common understanding as new information outweighs individual-level priors in the Bayesian framework. Instead, the parallel trends observation used by Gerber and Green (1999) as validation for their belief in unbiased learning is actually the most potent evidence against it: there is some irreducible partisan bias that separates political subgroups despite observation of some common picture of factual information. Indeed, this perspective has been more recently examined in analysis by Taber and Lodge (2006) that finds strong partisans, particularly those with the political sophistication to mount an informed defense, will downweight disconfirming arguments and lend more credibility to information that confirms their prior understanding. Applied to this case, the failure of partisans to reach a common understanding of the performance of the military institution should lead us to believe that a potentially partisan-motivated bias is at work.

Such thinking is at the core of this theory: an increasingly polarized and sorted public, subjected to different information flows and exhibiting different levels of cognitive bias, contributes to widening polarization in what should be an objective evaluation of institutional performance. As such, this theory envisions two complementary elements of the same evaluative process with regards to assessment of the military institution. First, the selective exposure hypothesis argues that partisans are predisposed to receive widely different types of information pertaining to military performance, shaping the usable store of data with which partisans issue judgments of credibility. Second, the partisans bias hypothesis argues that how partisans use new or newly-salient information in forming opinions differs greatly between subgroups, with affective polarization biases driving uneven levels of perceived military credibility. I incorporate competing arguments regarding the ability of individuals to update rationally (Gerber and Green 1999) or in a biased fashion (Bartels 2002 Gaines et al. 2007) when rendering a judgment 
on the reliability of the military institution and utilize a multi-method approach to address this question.

\section{Selective Information Exposure}

The first portion of my theory regards bias in information acquisition, which I argue could take on any combination of two non-mutually exclusive forms. The first is that partisans are subject to different volumes of information regarding military performance or organizational conduct. Demand-based reporting biases and voluntary selective exposure to certain outlets can result in the individual having far less probability of hearing new information. An individual may discredit reporting that focuses on the story or traffic a limited diversity of news outlets, allowing reporting biases to shape the information to which she is exposed. If information availability is minimal compared to other individuals, contrary updates are easier to dismiss out of hand as unreliable or aberrant. Bartels (2002) argues that off-hand rejection of new information "in extreme cases [...] may approach delusion" in its censoring of new updating data. In order to account for the possibility that media outlets with partisan audiences may exhibit this reporting bias, I structure H1A:

- H1A (Asymmetric Reporting): News outlets with established partisans audiences will report negative stories about the military at different rates.

The second form of information exposure bias I propose is that partisans are subject to different frames when military information is reported; on issues regarding military competence and professionalism, these stories may be presented in a way that insulates the institution from public criticism or highlights institutional failures. Even if H1A predicts certain outlets would under-report these stories, periods of conflict would still likely oblige reporting on war activities by biased media outlets to their audience. However, the nature of that reporting may be heavily subject to "lead story" effects and issue framing by focusing on some aspects of the military's performance and a war's conduct while ignoring or downplaying others (Iyengar and Kinder 1989). I capture this potential avenue of information selectivity in H1B:

- H1B (Asymmetric Framing): When negative military stories are reported, media outlets with established partisan audiences will exhibit different frames with respect to criticism/insulation of the military institution. 
In both cases, the events of reality fail to effectively update factual beliefs due to filtering by partisanfavored media sources. Given the direction of the partisan confidence gap, in which Republicans exhibit consistently higher levels of trust in the military, H1A predicts that conservative media outlets will under-report issues regarding military failures, strategic missteps, or professional misconduct when compared to centrist or progressive outlets. This would logically result in a Republican audience with less access to updating information by which to form new evaluations of the military. Whether this is the result of supply-side news biases, demand-side audience preferences, or a combination of both, is not the purview of this analysis, as all of them contribute to the logic of H1A. In addition, H1B predicts that when these stories are reported, they will be framed in such a way as to minimize direct damage to the prestige and credibility of the institution when compared to other outlets. I will test both of these hypotheses in the following section by analyzing reporting habits and patterns among news outlets with defined partisan audiences during the Iraq War. This period is particularly useful in testing the information exposure hypothesis because (1) new information about military conduct and performance was readily available and (2) this timeframe is characterized by some of the widest separation between partisans on military attitudes.

\section{Partisan Biases and Affective Polarization}

The second portion of my theory asserts that partisans are using different evaluative processes to transfer information into judgments about the credibility of the military institution. Conditional on new updating information reaching the audience, it still may be the case that partisans differ in how they evaluate the performance or institutional quality of the armed forces. However, difference in expressed opinion need not indicate the existence of pronounced partisan bias. I therefore consider three potential explanations for how partisans might arrive at different conclusions about the military institution in response to new or newly-salient information.

The first is that Republicans in society have a larger base of knowledge and working information about the military compared to others. According to this assertion, Republicans are not updating in a biased fashion. Instead, the incorporation of new information does not influence prior attitudes because that prior is based on a very high number of observations in their "running tally", against which a new piece of data is relatively insignificant. If Republican respondents are selectively predisposed to have much higher amounts of information about the military institution, have greater expressed inter- 
est in military issues, or have more direct familiarity with the institution compared to Democrats and Independents, it may follow that their prior attitudes are harder to reverse because of the relative size between existing beliefs and new information. From this argument I form the following hypothesis:

- H2A (Bayesian Updating): Certain partisans possess a larger store of information regarding the military institution ex ante, making updating information relatively ineffectual compared to others.

The implications of this hypothesis would be that Republicans have greater interest in military affairs, possess greater command of knowledge in issues regarding the institution, or have higher levels of direct exposure to the military as an organization. As a result, new information regarding military affairs would have a much larger prior to influence compared to centrists or liberals with comparatively less knowledge about the military. I will test this hypothesis using both observational and experimental data regarding Republican knowledge and interest in security issues and the military institution more broadly.

The second potential explanation for the partisan separation in expressed confidence I consider comes from the counterarguments of Gerber and Green (1999); if individuals simply have different perceptions of what is preferable, disparate attitudes need not be indicative of biased processing. In its broadest form, the debate over the causes of public trust is the product of divergent attitudes over directionality. The institutionalist tradition argues a reverse process in which institutional outcomes drive requisite public trust. In this tradition, expressed trust in institutions is endogenous, a rational valuation of those institutions based on their perceived performance (Hetherington 1998). This top-down process of creating confidence in institutions requires that government produce positive outcomes that are, in turn, rewarded by the public with expressions of trust in the institutions that are responsible for those outcomes. Mishler and Rose (2001) seize on one of the main limitations of this field in that, "although institutional theories agree that political trust is endogenous, they disagree about which aspects of performance are important or how performance is assessed." In order to correct this gap with regards to evaluation of the military, I establish several categories of potential conduct.

Most of the limited study dedicated to understanding institutional evaluations of the military has relied on institutionalist theory, arguing that public trust is a rational valuation of perceived performance. There have been numerous efforts to characterize what types of behavior or performance individuals 
value most with regards to the military, ranging from purely transactional evaluations of battlefield performance (Gronke and Feaver 2001; King and Karabell 2002) to organizational professionalism (Hill, Wong, and Gerras 2013. Burbach 2017). As some have noted, the specific challenge in explaining patterns of trust in the military institution comes from the difficulty in capturing a meaningful metric of performance (Garb and Malesic 2016; Yang and Holzer 2006). However, comparatively few have considered that these criteria might differ based on the political or ideological leanings of the individual.

I therefore organize the existing literature on military confidence to create three non-mutually exclusive categories of criteria for assessing the military institution. The first potential driver of public esteem for the military is, as Gronke and Feaver remark, "the most obvious" one, a purely transactional assessment of the institution based on its performance in warfare. I categorize this class of criteria as performance evaluations. As the military's singular function within society is to fight and win its nation's wars, it follows that the institution's performance under these conditions should provide the clearest signal to the public as to its competency and quality.

A second theoretical approach takes into account the importance of organizational practices, that public regard for the military institution is driven by perceived institutional integrity, ethical quality, and embodiment of cherished social norms. Following the nomenclature of King and Karabell $(\overline{2002})$ and Burbach (2017), I categorize this class of explanations as professionalism evaluations. While achieving some quantifiable link between institutional practices and public esteem has been difficult to ascertain, I nonetheless consider this explanation potentially powerful given the concurrence of internal military reforms and rising public esteem during the post-Vietnam era. This does not suggest that concern over the military's moral character supplants public desire for a capable military. For our purposes, the professionalism class of evaluations asserts that individuals in society expect the military to embody certain virtues or maintain organizational standards of integrity while preserving warfighting capacity. However, it also assumes that the more active process in public valuation of the institution is not an overt display of battlefield prowess so much as fair practices and accountability.

Third, I capture potential responses to the military's development as an impartial and unbiased elite community in society. Though civil-military relations scholars have debated various models for the optimal distribution of political and military power, there is broad consensus across most for the virtue 
and necessity of an apolitical military (Huntington 1957; Feaver and Kohn 2001; Feaver 1999; Dempsey 2009 Golby, Feaver, and Dropp 2017). The typology of institutions laid out by Rothstein and Stolle (2007) includes the armed forces as part of the class of "order institutions" valued for their impartiality and ability to fairly administer policy. While military elites have become more prevalent in the political discourse domestically, Hill, Wong, and Gerras (2013) argue that it is the continued restraint of the institution from engaging in partisan activity and its deeply-ingrained deference to civilian leaders that has contributed to high public confidence. I characterize this class of criteria as non-partisan evaluations, distinct from performance and professionalism preferences in that the public is responding not to battlefield outcomes or organizational ethics, but general trustworthiness and reliability. From these three preference sets I form the following hypothesis:

- H2B (Divergent Preferences): Certain partisans will value different classes of military behavior (performance, professionalism, non-partisanship) more in rendering their opinions about institutional credibility.

These different classes of evaluative criteria allow for the possibility that partisans across society merely have divergent preferences with regards to the optimal behavior of their military. As a result, H2B argues that partisan divergence in expressed confidence is the result of different political subsets expecting certain types of behavior from the military and rewarding or punishing the institution in accordance with their perceived accomplishments or failures in that class. This would be observable if partisans displayed clear and distinct prioritization in which types of military behavior affected their perceptions of trust. I test this hypothesis using experimental methods designed to measure partisan preferences for military performance.

However, if partisan priors ex ante regarding knowledge of the military institution are comparable and partisan individuals express no clear preference for military behavior relative to each other, we can no longer assume that unbiased learning is taking place. In this case, a difference in expressed opinion at the conclusion of the updating process between partisan groups is attributable to cognitive biases that prevent an updated evaluation of the institution. Conditional on access to useful information on military failures, one would expect a commensurate re-evaluation of the institution that took this information into account; if they did not, some biased process is affecting the nature of that evaluation: 
- H2C (Partisan Bias): Certain partisans employ a biased process in evaluating the credibility of the military institution in response to new information.

Both H2A and H2B allow for an unbiased process of evaluation to take place: the former attributes rigid confidence in the military to the notion that new information is less influential compared to a larger base of knowledge, while the latter contends that partisans simply disagree on the most important criteria by which to evaluate the military's credibility. However, $\mathrm{H} 2 \mathrm{C}$ captures the case in which, even without more ex ante information on the military and with the ability to express preferences differently, a subset of individuals will actively reject updating information or interpret the meaning of that information in a way that insulates the military institution from damage.

Why might this be the case? A substantial literature in political science has sought to investigate the nature of partisan polarization in American society, particularly with regard to the effect of partisan sorting on the extremity of issue positions and out-group animus (Mason 2015: Abramowitz and Saunders 2008; Bafumi and Shapiro 2009). A critical distinction is made between traditional issue polarization and social or affective polarization, in which partisans - sorted into closer party-ideology alignment - increase both out-group animus and in-group bias (Mason 2015 Iyengar and Westwood 2015. Iyengar, Sood, and Lelkes 2012). In this framework, partisan identity carries with it a social dimension that can distort objective thought processes regarding policy or governmental quality. Bafumi and Shapiro $(2009)$ argue more pointedly that the influence of solidified partisan attitudes may have potentially damaging implications for rational opinion formation more broadly (emphasis added by author):

Strong partisan attitudes may lead to rigidity of attitudes and opinions in the face of new and credible discrepant information. Not only might such new information be avoided through selective exposure, but its accuracy and validity might be denied as a result of "motivated bias" or flawed reasoning or no reasoning at all.

Expressions of confidence in the military, within this framework, are not rational evaluations of institutional credibility, but emotional statements of partisan and social identity. Strong partisans have been found to be particularly more likely to counter-argue contrary information (Taber and Lodge 2006), to express anger or bias in response to threats to party status or prestige (Huddy, Mason, and Aaroe 2015), or in the case of political conservatives, to express far more dogmatic thought processes or ideological intensity (Nyhan and Reifler 2010, Lelkes and Sniderman 2016). While many of these patterns have been found in attitudes about co-partisans, it would be particularly curious to find such 
a dynamic at work in attitudes about an institution with a decidedly non-partisan structure and code of ethics. Nonetheless, I propose through $\mathrm{H} 2 \mathrm{C}$ that this process is at work, particularly among strong conservative partisans, influencing how new information about the military is received and processed.

In this section I have argued for the use of a dynamic theory in order to explain partisan polarization on perceived military credibility. While issued-based explanations are suitable for explaining a static or baseline "confidence gap" between partisans, the persistence and expansion of this gap over time requires a different theoretical approach. This theory argues that special attention must be paid to (1) how individuals receive new information about the military institution and (2) the pathologies that partisans exhibit in how that information is used. In the first part of the theory, I propose two hypotheses arguing that partisan audiences are exposed to vastly different information environments with regards to the volume and tone of military information. In the second part, while I account for the possibility that divergent attitudes are the product of rational processes, I argue that partisan bias - particularly among the strongest or "sorted" partisans - may be driving the broader pattern of polarization we observe.

\section{Partisan Exposure to Military Performance}

In this section I evaluate the validity of information exposure explanations for partisan polarization in military confidence. The institutionalist school discussed above requires that the public issue judgments of the performance of an institution based on its perceived quality. However, it is a central contention of this analysis that even if individuals have a variety of options in how to evaluate the military institution given new information, they are still largely reliant on third parties to provide that information. Barring personal experience or direct exposure to the institution's actions, many individuals instead rely on information from other elite communities in society, such as political leaders and the news media when forming attitudes on institutions (Nye 1997; Hanitzsch and Berganza 2012; Wiegand and Paletz 2001). This assumption is particularly valid when considering the military institution, given its increasing distance from the mass public and the decreasing probability of the average citizen having first-hand information on military performance (Liebert and Golby 2017). Due to the centrality of these additional sources on shaping the information environment, I examine the importance of media reporting habits on the information environment to which partisans are exposed. 
Partisan political identity serves as the principal lens through which I envision individuals gaining information about institutional performance. For a structurally and normatively apolitical institution as the military, partisan alignment should theoretically provide no additional information that is predictive of performance evaluation. However, as the previous descriptive regressions and factor analysis have revealed, this is not the case. Instead, I argue that polarization in expressed trust for the military is partially the result of such expressions being subsumed into partisan identities, maintained by controlled information exposure. As Achen and Bartels (2017) observe, a partisan news source "identifies friends and enemies, it supplies talking points, and it tells people how to think and what to believe." If partisan individuals rely on these sources for information on the military institution, it is to those source we must direct our attention.

News information consumption habits vary wildly between partisan subgroups. Conservative Republicans are far more likely to consume news media from a single source rather than a multitude of news outlets; as such, we should expect that the reliance on third-party information about the military institution is more potent among these individuals, given the increased likelihood for more substantively coherent information. ${ }^{4}$ However, as previously discussed, the existence of media "echo-chambers", particularly among established partisans, serves to minimize exposure to contrary information (Jamieson and Cappella 2008), "reinforce existing attitudes and beliefs" (Iyengar and Hahn 2009), and increase alignment with pro-attitudinal information (Stroud 2008). Furthermore, the active distrust among political conservatives for a much wider swath of media sources compounds this effect: in addition to trafficking a limited plurality of information sources, this partisan subgroup is also more likely to reject contrary information as non-credible depending on its source. Polling on this phenomenon reveals that while $62 \%$ of Democrats believe that the news media "gets the facts straight", only $14 \%$ of Republicans feel the same way; this distrust of the press permeates every medium, from television to print media to internet news. ${ }^{5}$

\footnotetext{
${ }^{4}$ Pew reports that $47 \%$ of individuals identifying as "conservative" or "very conservative" obtain news on government and politics from a single source: FOX News. This compares to smaller outlet followings among political liberals, where MSNBC and CNN have followings of $12 \%$ and $15 \%$, respectively. "Consistent" conservatives are also far more likely to actively distrust other media outlets than liberals; of the 36 media outlets surveyed, conservatives held more distrust than trust for 24 of them, compared to 8 out of 36 among liberals. "Political Polarization and Media Habits: From Fox News to Facebook, How Liberals and Conservatives Keep Up with Politics", Pew Research Center, October 21, 2014.

${ }^{5}$ Andrew Dugan and Zac Auter, "Republicans', Democrats' Views of Media Accuracy Diverge", Gallup, August 25, 2017.
} 
If stories that otherwise might update their opinion of the military's performance or professionalism are rejected or not widely reported by their preferred media outlets, strong partisans may be more likely to dismiss singular disconfirming stories as either untrustworthy, biased, or unrepresentative of the institution writ large. The impact of partisanship has been demonstrated to have a marked effect on perceptions of military operations; respondents identifying as Republican during the Bush administration were more likely to underestimate the number of casualties the US had sustained in the Iraq conflict and more likely to have a higher perceived probability of success for the war's outcome (Berinsky 2007). Rather than support for a conflict specifically, I explore the feasibility of H1A and H1B in that partisans update - or fail to update - their impressions of the military institution in response to different patterns of reporting on war performance and military professionalism. The role of individual level political identity, particularly among ideologically "sorted" partisans, may help to explain the broader trend of polarization in military confidence we observe.

\section{Evaluating Asymmetric Reporting Hypothesis}

In order to assess the plausibility of divergent information availability across news outlets with established partisan audiences, I analyze reporting trends on the Iraq War in 2007 across major media sources in different forms. This period is remarkable in that it was arguably the most politically contentious and empirically the most deadly year of the Iraq War; I argue that this period of time exhibits the high watermark of war reporting and public accessibility to updating information about military capability and effectiveness, making it a highly useful case for analysis. The first dimension I examine is the frequency with which stories that might otherwise update partisan attitudes on the military are reported across different sources. In order to test the theory that conservative sources may under report stories of war performance (H1A), I utilize the Pew Research Center News Content Index (NCI) dataset, which records and codes the duration, substance, and frequency of online, radio, television, and print media news segments based on a series of rotating sampling processes. ${ }^{6}$

I specifically examine the prominence and frequency of stories coded in the NCI dataset as pertaining to combat events, casualties, reconstructions efforts, evaluations of the Iraq troop surge, and other events relevant to the conduct of the war's execution. These stories are coded distinctly from "homefront" stories involving memorialization or Iraq veteran issues and "policy debate" stories regard-

\footnotetext{
${ }^{6}$ See Appendix C for expanded description of NCI sampling processes and procedures.
} 
ing political ramifications, general strategy, or anti-war efforts. As a result, this category exclusively captures news stories that best reflect the performance of the military during the critical "surge" period to a national audience. I focus on cable news outlets with the highest ratings exposure in 2007 (CNN, MSNBC, FOX) and print media outlets classified as "Tier 1" by Pew based on national distribution and circulation (The New York Times, The Washington Post, and Wall Street Journal). I also include radio programs with headline feeds (ABC News Headlines), national audiences (NPR), and the highest cumulative audience programs in 2007 (Sean Hannity, Rush Limbaugh). ${ }^{7}$ From this I am able to capture a fairly adequate picture of the media environment partisans would have experienced regarding information on the military's performance in Iraq.

Figure 1 displays the results of this analysis for the major cable news channels. As previously stated, a preponderance of self-identified conservatives consume most of their news from FOX, while liberals and centrists are more likely to sample from a variety of sources including CNN, MSNBC, and PBS. For this reason, I focus on the contrast between these groups of media outlets when reporting on the Combat Events category. Evident from these results is that FOX devotes low levels of average air time to such stories in 2007, with segments of far shorter collective duration compared to the other news channels. The most notable gaps in relative coverage between outlets are concurrent with increased concern of the refugee crisis (March), the deadliest months of the year (April-July), and the period following General David Petraeus' report to Congress (September). During these periods, conservative media is out-reported by as much as two- to three-times by other networks on these stories. As reported in Table 2, over the entire measured period of 2007, the average percentage of daily coverage time spent on ICE stories on FOX amounted to roughly half of that spent by CNN and MSNBC, and close to a third of that spent by PBS. Coverage of Iraq stories more generally, including homefront and policy stories, exhibit and even starker contrast between outlets.

I replicate this analysis to include other forms of news transmission. Incorporation of print newspapers with national distribution yields a similar pattern of reporting asymmetry. Figure 2(a) captures the prominence given to ICE stories over time by each of the three Tier 1 print sources sampled; while

\footnotetext{
${ }^{7}$ For television and radio programs, I generate "\% of Newshole" by calculating a daily total of duration (in on-air seconds) spent on the Iraq Combat Events topic by each source, divided by the total number of on-air seconds sampled by the NCI database. This yields a daily percentage of the on-air time devoted to Iraq Combat Event stories per day, per source. For print media, I reverse-coded the "prominence" variable from the NCI dataset that rates all newspaper stories on a five-point scale based on location in the paper's print edition (most prominent, second most prominent, other-above the fold, etc...), taking the daily average of these to create a "Prominence Proportion" per day, per source.
} 
Figure 1: Media Coverage of Iraq Combat Events by Source, 2007

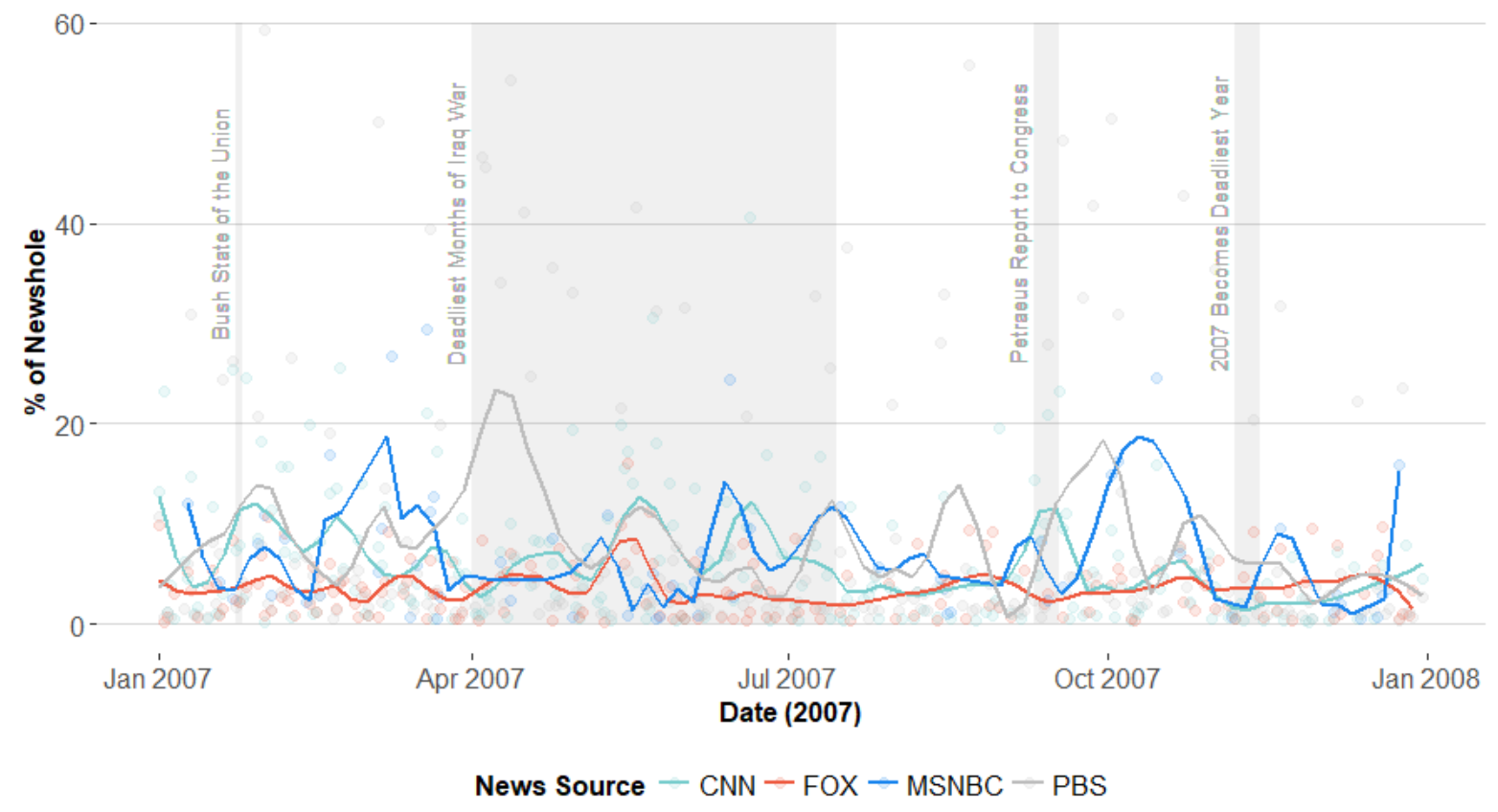

NOTE: This figure depicts media coverage of Iraq Combat Events (ICE) and related news stories as coded by Pew Research News Content Index (NCI) Dataset. Points represent day totals for percent of newshole for cable news sources with largest audience reach. LOESS smoothers are added to depict broader trend of moving averages over time (span =0.10). Shaded periods indicate several Iraq-related events of interest during the course of the 2007 news year, including announcement of the "surge" strategy (State of the Union), the Congressional report on its progress (Petraeus Report), and sharp increases in coalition casualties.

the Wall Street Journal is not a conservative media "chamber" as FOX is for television, recent study has revealed it is the only newspaper that self-identified conservatives trust more than they distrust. ${ }^{8}$ Even at minimum span, the LOESS smoother cannot capture a yearly trend of reporting for WSJ because there are too few data points of reporting on these stories. This should not be surprising; compared to The New York Times and The Washington Post, the Journal is far more business-focused and devotes less column inches to foreign affairs on the whole. However, it remains that among preferred print media sources, an even wider disparity in access to updating information about the military's war performance exists in this medium than in cable news.

I include consideration of radio sources as an additional medium; of the top five media sources

\footnotetext{
${ }^{8}$ While actually quite centrist based on the ideological distribution of its audience, WSJ is in fact the only news sources out of 36 in the Pew study in which individuals from the entire ideological spectrum express trust over distrust; for this reason, I incorporate this paper as the conservative source for print media as it is the most likely to be consumed by right partisans.
} 
Table 2: Descriptive Statistics, Iraq War Reporting: Cable News (2007)

\begin{tabular}{lcccc}
\hline \hline & \multicolumn{4}{c}{ Mean Percentage of Sampled Newshole } \\
\cline { 2 - 5 } & PBS & CNN & MSNBC & FOX News \\
News Source & $(1)$ & $(2)$ & $(3)$ & $(4)$ \\
\hline Combat Events & 9.18 & 6.12 & 6.85 & 3.62 \\
& $(<0.001)$ & $(<0.001)$ & $(<0.001)$ & \\
Domestic/Homefront & 27.12 & 6.57 & 10.75 & 4.62 \\
& $(<0.001)$ & $(0.07)$ & $(0.01)$ & \\
Policy Debate & 26.38 & 13.03 & 25.28 & 9.97 \\
& $(<0.001)$ & $(0.01)$ & $(<0.001)$ & \\
\hline Observations & 431 & 468 & 243 & 394 \\
\hline \hline
\end{tabular}

NOTE: Reported figures depict average percent of daily newshole dedicated to segments on Iraq War stories across the entire 2007 news year. Values in parentheses () indicate p-values for two-tailed t-test for difference in means between reported news source and FOX News as reference category.

utilized by consistent conservatives, FOX News (88\%) and local news (50\%) are followed closely by radio programs from Sean Hannity (45\%) and Rush Limbaugh (43\%). ${ }^{9}$ However, Figure 2(b) reveals that these do not constitute an unaccounted channel by which information about war events might be communicated. Again, the LOESS smoother has too few reporting points to calculate a yearly trend from the conservative outlets. This is in comparison to National Public Radio and ABC News Headlines which regularly spend in excess of $10 \%$ of their sampled air-time on ground events and actions coming from the Iraq War. As a well-trafficked news medium by self-identified political conservatives, these findings contribute to the pattern developed in Figures 1 and 2(a), in which network news entities were far more likely to report on ICE during this period of high military activity.

In addition to stories regarding military performance, I extended analysis of the same cable news sources to reporting on specific "sub-story lines" coded by the NCI dataset outside the Iraq Combat Events category. ${ }^{10}$ Noticeably less airtime was committed by FOX News to stories such as the troop increase, the Pat Tillman friendly-fire cover-up scandal, and stories comparing the conflict in Iraq to the Vietnam War. I conducted a similar extension of reporting habits across print media sources on military

\footnotetext{
${ }^{9}$ Percentages of conservative viewership captured by Pew Research, 2014. Pew Research Center, October 2014, "Political Polarization and Media Habits"

${ }^{10}$ The Pew NCI dataset codes component sub-story lines that collectively compose broader or "big stories". For example, Iraq combat events are broadly coded together (storyid=100), but include more specific categorizations based on their nature as "Combat/violence/casualties" (substoryline=100001), "Iraqi refugees" (substoryline=100010), or "Evaluations of US troop surge" (substoryline=100014). Graphical depictions of outlet variation in reporting times is available in Appendix B.
} 
Figure 2: Media Coverage of Iraq Combat Events by Source, 2007

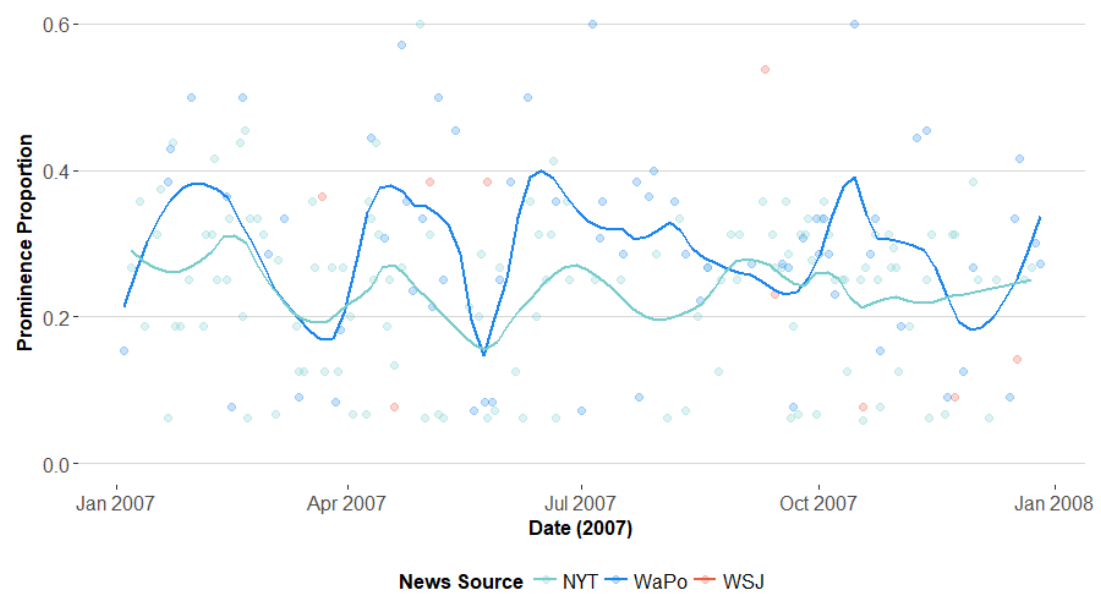

(a) Print Media Coverage

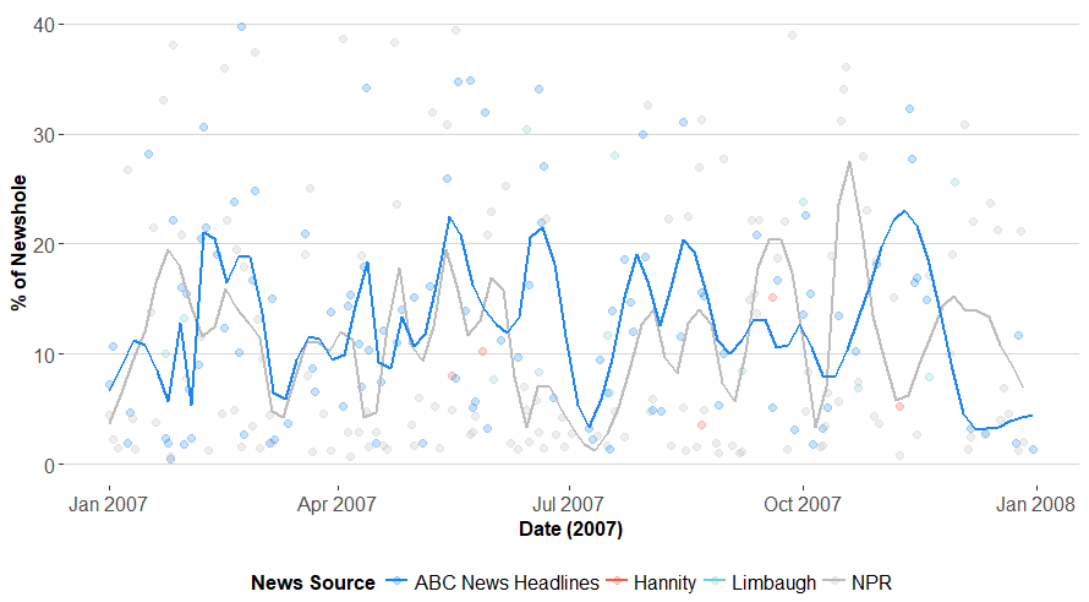

(b) Radio Source Coverage

NOTE: This figure depicts media coverage of Iraq Combat Events (ICE) and related news stories as coded by Pew Research News Content Index (NCI) Dataset. Points represent day totals for percent of newshole or prominence proportion. LOESS smoothers are added to depict broader trend of moving averages over time (span $=0.15)$.

scandals including some outside the 2007 timeframe, which shows that Wall Street Journal readers were far less likely to be exposed to any stories regarding the Abu Ghraib prison scandal (2004), the Haditha massacre (2006), the Walter Reed Medical Facility scandal (2007), or stories regarding sexual assault in the military (2013) than readers of The New York Times or The Washington Post over the same periods. ${ }^{11}$

\footnotetext{
${ }^{11}$ Graphical depiction of print media reporting on these stories is available in Appendix B.
} 
The media environment depicted in this analysis reveals a consistent asymmetry in reporting across conservative and left-center news sources on the subject of Iraq war events, more specifically the stories about casualties, reconstruction frustrations, and regular assessments of the "surge" strategy that might otherwise have informed a new assessment of the military's execution of the campaign. As a critical story topic for informing the public on military performance, the difference in information between partisan subgroups comes into closer focus. Media outlets such as FOX News, more heavily trafficked by conservative Republicans, were less likely to report on military scandals or poor wartime outcomes. As a result, I find strong support for the assertions of H1A, in that partisans on both sides of the political spectrum would have had different levels of availability to updating information on military performance and institutional quality. In the next section, I examine how this asymmetry in reporting is potentially compounded by uneven framing of military information across news sources.

\section{Evaluating Asymmetric Framing Hypothesis}

Examining high-volume news periods like the 2007 phase of the Iraq War provides a unique picture of the reporting patterns of the various news sources frequented by partisans during an important opportunity of evaluation for the military. One potential critique of these patterns is that they speak to descriptive patterns of story frequency, rather than the substance of certain stories - such as Iraq War events when they are reported. It is reasonable to assert that certain sub-storylines, such as the "Comparisons to Vietnam" or "Pat Tillman Scandal" stories, are damaging enough to military prestige in themselves that a gap in reporting frequency likely results in a commensurate gap in substantive portrayal of the institution. The difficulty US forces encountered during this critical period, with mounting casualties, the "surge" of several brigades into the Baghdad area, and high-level leadership turnover, made even objective reporting on battlefield events potentially damaging news about military performance. Collectively, we observe strong evidence for H1A in the reporting patterns depicted during this period for individuals to update their judgments on military performance; across different media and sources, conservative outlets consistently reported less on war events and combat costs than centrist or left-leaning media outlets.

However, testing the validity of H1B required analysis of substantive data on reporting content. Selecting on the same three primary television news outlets from earlier (CNN, MSNBC, and FOX), I utilized the LexisNexis database to collect all broadcast transcripts between January 1, 2007 and December 31, 2007 which contained the term or root iraq/iraqi and were sub-coded as pertaining to the 
Iraq War. After removing missing data and detectable duplicates, the final dataset of 1,951 broadcast transcripts captured the substantive discussion of news segments dealing primarily with the Iraq War during the same timeframe analyzed previously. This dataset served as the textual corpus for content analysis on the topic distribution across news sources within the Iraq War subject.

Unsupervised machine learning and text-as-data analysis have become an increasingly effective tool for allowing a textual corpus to inform the researcher about the variety of substantive topics being addressed in a body of text. Here I use an extension of the Latent Dirichlet Allocation (LDA) multilevel architecture, the Structural Topic Model (STM), in order to utilize the text of the transcripts themselves to inform what subjects are being discussed across news sources. The STM pre-supposes a set of $k$ potential topics being discussed in the text, across which a probabilistic distribution of words exists, and that documents are similarly a mixed distribution across topics (Blei, $\mathrm{Ng}$, and Jordan 2003 Roberts, Stewart, and Tingley 2014). ${ }^{12}$ This allows the text to characterize its own topic distribution based on those words that occur most frequently.

After collection, I then pre-process the transcripts to produce a functional version of the dataset as a textual corpus (stemmed, lemmatized, and stripped of punctuation, numbers, and capitalization), I ran several topic models on the constituent broadcast segments. Several iterations allowed for me to remove proper nouns with high frequency, such as the names of reporters and commentators referenced directly. Once a sufficient number of these "stop words" had been removed, the I implemented a 35topic structural model to ascertain the thematic threads of the transcripts. Using these words and the substantive material in the top ten articles best captured by each topic, I labeled the topics according to the content of reporting and the tone of the discussion.

Using the news source as a covariate, I am able to plot the predicted topic proportion over the entire text corpus for each news source with uncertainty bands at the $95 \%$ level. Figure 3 depicts some of the more coherent and clearly identifiable topics based on word probability and the substance of the broadcasts themselves. Each graphical depiction shows how different topics composed various levels of the content share across the media outlets - expressed as the mean topic proportion - given the substance of the transcripts. Topics depicted in Figure 3(a) indicate those with notably higher frequency in the

\footnotetext{
2014).

${ }^{12}$ For more technical description of the quantitative methods behind STM, reference (Roberts, Stewart, and Tingley
} 
Figure 3: Expected Topic Proportion by Source (STM), Cable Broadcast Transcripts, 2007
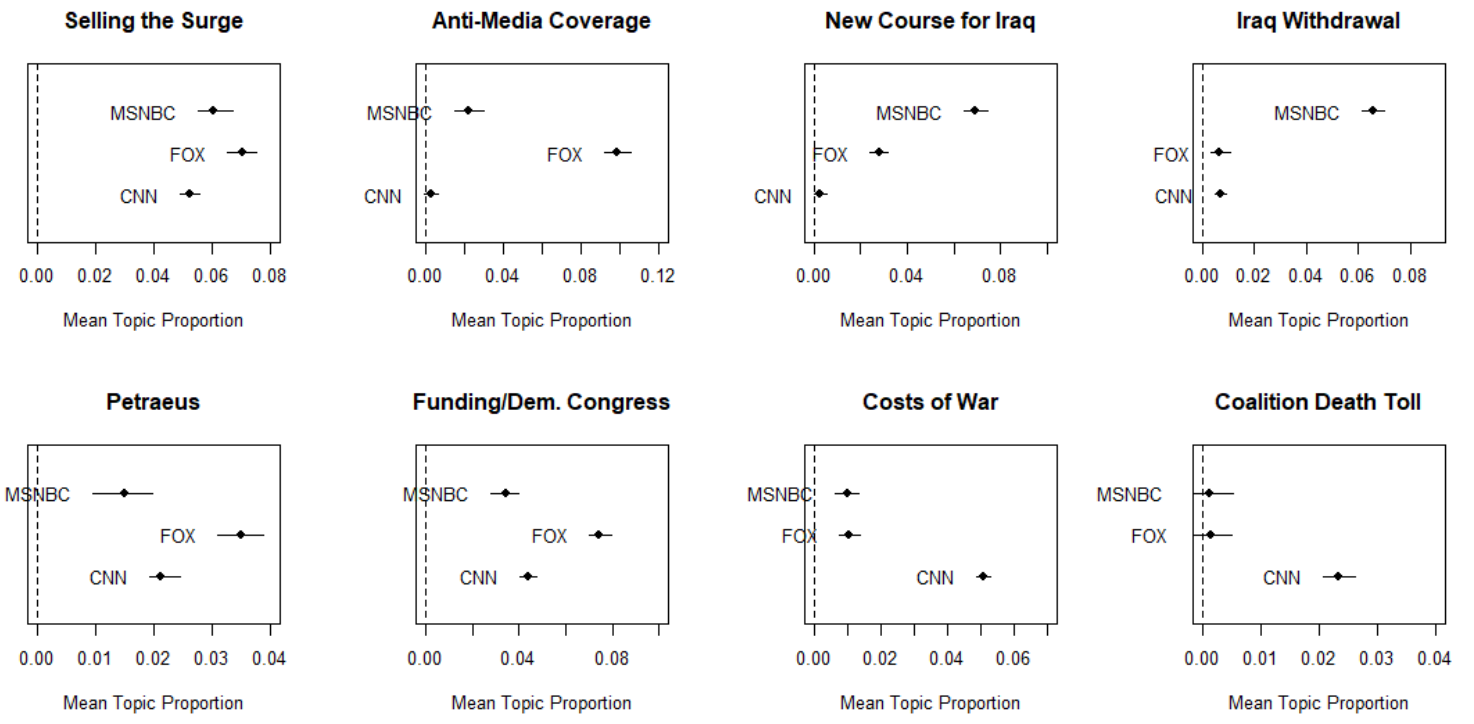

(a) FOX News Topics

(b) MSNBC/CNN Topics

NOTE: This figure depicts the expected topic proportion for each of these seven topics estimated by the topic model by source. Topics are grouped by the media outlet that led reporting on those topics. Labels indicate substantive impact of frequently occurring words and the content of top ten broadcast transcripts captured by topic prevalence. Uncertainty bands represent 95\% confidence intervals following 100 simulations. With K=35, the average expected mean topic proportion $\approx .028$.

FOX subset of the corpus, while those topics in Figure 3(b) were more prevalent in the MSNBC and CNN transcripts. ${ }^{13}$

Indeed, many of the patterns identified during analysis of the Pew dataset seem to re-emerge. The MSNBC and CNN-favored topics in Figure 3(b) included direct commentary of material losses, strategic frustration, and mounting coalition military casualties. The "New Course in Iraq" and "Iraq Withdrawal" topics, most heavily reported by MSNBC, were temporally frequent around the announcement of the "surge" strategy in early 2007 and later in the year when the "surge" strategy was coming under increasing scrutiny. The stories drew increased attention to the debate over the viability of the new strategy and discussion of a timetable for removing US forces. Media focus shifting to how the 2008 presidential candidates planned to handle the war came with a commensurate increase in commentary on the complications with the "surge". The "Costs of War" and "Coalition Death Toll" topics favored by CNN coincided with periods of high-casualties for the coalition, including the 3,000-killed milestone

\footnotetext{
${ }^{13}$ Brief metadata summary of top-ten news articles depicted in Appendix B.
} 
and specific stories on war dead and missing. Again, these topics were more concerned with the personnel and material losses of the war and the military's difficulty in navigating the Iraq conflict.

However, topics more heavily reported in FOX transcripts, shows in Figure 3(a), represented a different tone and thematic focus on military information. Unlike the previous topics that spent considerable airtime discussing the military's complications in Iraq, FOX reporting focused on political battles with Democrats over war-funding, defense of the "surge", and lateral admonishment of how other media sources were covering the war. The "Petraeus" and "Selling the Surge" topics were characterized by direct interviews with commanding general David Petraeus or Republican political elites and supportive commentary of President Bush's "surge" strategy. In addition to allowing the commanding general to directly advocate for the troop increase and his upcoming report to Congress, these broadcasts often led with such remarks as "in Iraq, the surge is working" or critiques of Democratic opposition to the war's continuation. ${ }^{14}$

Framing of the war as a political battle with Democrats and left-wing media were generally more popular topics in the FOX transcripts as well. Broadcasts in the "Selling the Surge" and "Funding/Dem. Congress" topics often led with comments such as "can Democrats force the president to accept a timetable for pulling out?" and "Democrats want to shell out $\$ 21$ billion, in all, on non-military programs. And this is part of their war bill?". ${ }^{15}$ FOX most heavily outpaced other networks in its reporting of the political battle between President Bush and Congressional Democrats and the manner in which the war was being reported in other outlets. The "Anti-Media Coverage" topic was characterized by admonishments of a PBS war documentary "leaving many conservatives up in arms", critical stories about "how the far left is handling the U.S. military", and negative reports on how The Washington Post, NBC News, and "the left wing press" were reporting on the military. ${ }^{16}$ When newly-retired Lieutenant General Ricardo Sanchez issued openly critical statements about the war's governing strategy, the FOX story reported that "lost in the outrage was another statement from Sanchez, condemning media outlets for having political agendas and blasting news agencies for putting soldiers in harm's way". ${ }^{17}$

\footnotetext{
14 "Interview with David Petraeus", FOX News, Chris Wallace, December 23, 2007.

15 "Interview with Senators Graham/Levin", FOX News, Chris Wallace, April 15, 2007; "Interview with House Minority Leader John Boehner", FOX News, Neil Cavuto, March 21, 2007

16 "New Documentary on War Has Some Up in Arms", FOX News, Alan Colmes, April 24, 2007; "Talking Points Memo and Impact: Who Respects the Troops", FOX News, Bill O'Reilly, February 8, 2007; "Talking Points Memo and Top Story", FOX News, Bill O'Reilly, April 24, 2007

17 "Retired General Blasts Iraq War Effort, Media Coverage", FOX News, Alan Colmes, October 15, 2007.
} 
Across these topics, we observe support for an asymmetric framing pattern (H1B) during this critical reporting period. As individuals sought out and received various types of information regarding the conduct of the war, they were subject to different distributions of framing or "lead story" effects based on which outlet they were likely to traffic. Whereas centrist and liberal media sources were more likely to frame discussion of the Iraq war as a dialogue on military frustrations, personnel and material loss, rising sectarian violence, or discussion of a rapid withdrawal, conservative outlets were more likely to discuss the conflict in terms of homefront political fights over funding and the "surge", the Democratic opposition in Congress, or criticism of how other media outlets were reporting on the military. In addition to spending less time discussing the military's performance on the ground, these topics often came to the defense of the military institution by insisting that other media outlets were subverting the armed forces or that Congressional Democrats were harming the war effort.

Given the patterns of reporting measured in the preceding section, these results indicate a strongly skewed information environment between partisans with regards to the volume and content of information they received about the military. The result, particularly among conservative Republicans, is a decidedly "one-sided information flow" whose substance is far more partisan (Zaller 1992 Feldman, Huddy, and Marcus 2015). Given the increased reliance of this partisan subset for fewer news sources, these individuals are less likely to encounter contrary information outside a unified narrative. As I will discuss in the next section, strong partisans who are reliant on a select few media outlets may also be particularly susceptible to biased updating when presented with new and contradictory information.

\section{Partisan Bias and Military Credibility}

I now turn to the second part of my dynamic theory, focusing on the way partisans use new or newlysalient information to update their evaluations of the military institution. As discussed previously, I argue that the partisan confidence gap is also the result of biased processing of information critical of the military and its conduct; however, I also consider potential explanations that might otherwise allow for divergent opinions without biased updating. In order to test this suite of hypotheses regarding interpretation of information, I structure an experimental analysis that tests how partisans respond to priming information about the institutional quality of the armed forces, allowing them to express disfavor for different types of military misconduct or failures. 


\section{Research Design}

Using a design similar to that used by Ladd (2010) in a study of public attitudes on media behavior, the following experiment leverages a broad literature in social psychological studies of public attitude measurement through survey collections. ${ }^{18}$ Zaller and Feldman $(1992)$ develop a model for expressed public opinion as a probabilistic draw from a running count of impressions and experiences. Based on accessibility to information, individuals average across all memorable information when forming answers to public opinion queries, with the effect of "ideas recently made salient" being the most influential. The introduction of new or newly-salient information shaping expressed attitudes falls in line with established "top of the head" models of public opinion measurement, as well as experimental "framing" designs bringing specific information to the forefront of the individual's consideration (Taylor and Fiske 1978 Chong and Druckman 2007). Collectively, these theoretical concepts offer an empirical strategy for measuring expressed attitudes on subjects such as institutional confidence. Experimental framing can raise the short-term salience of specific information in line with the institutionalist hypotheses already developed, providing an opportunity to measure the effect of specific actions by the military on public confidence in that institution.

I construct a experimental environment wherein individuals are subjected to updating information that increases the salience of institutional quality in the military. Respondents were drawn from a nationally-representative opt-in panel through YouGov in March 2017, resulting in a final sample of 1,000 individuals randomly assigned to one of four experimental conditions. The control condition was asked two questions regarding their level of interest in news stories regarding US foreign policy and military operations, but unlike the treatment groups read no news stories or priming vignettes. This group served as the statistical baseline for confidence levels in three measured institutions - the military, the presidency, and the Congress - which were measured on an 11-point scale following the two news interest questions.

\footnotetext{
${ }^{18}$ Ladd $(2010)$ himself uses a similar formulation of Gilens $(2001)$, where even though the question asks about awareness of the story, this is not the measurable variable of interest; because the experiment is probing negative attitudes, the intent is to merely bring the information to the top of the respondent's head without drawing attention to the treatment. My own design differs from Ladd's in several ways. First, the use of a more compact scale for measurement of trust (rather than the feeling thermometer employed by Ladd for measuring attitudes on the media). Second, the news stories are meant as priming information in themselves, whereas the Ladd study uses elite criticism of the media institution as priming information. I adopt a similar strategy for measuring the control condition, where the only measurable variable is whether the respondent heard the story.
} 
All respondents were prompted that the study was measuring the extent to which stories about security issues and the military were reaching the public. In the control condition, respondents were asked (1) if they actively followed news stories about US foreign policy and (2) about US military operations. Each of the other three treatment groups was respectively prompted with two news snippets describing stories related to the military that had occurred in the last several years and asked if they had heard these stories. All groups were then asked at the end to measure their level of confidence in the military, the presidency, and Congress as well. The news stories given to each group were structured to vary the content of new information according to three classes of divergent preference criteria discussed previously. The first treatment group (non-partisan) was prompted with news stories that detailed partisan activity by retired military officers during the 2012 and 2016 presidential campaigns. The stories discussed large blocs of retired generals and admirals who had openly endorsed candidates Barack Obama, Mitt Romney, Donald Trump, and Hillary Clinton. This was designed to allow respondents to express preferences of military behavior in terms of non-partisanship and objectivity.

The second treatment group (performance) was exposed to two stories that detailed battlefield ineffectiveness or incompetence in the Iraq and Afghanistan wars, including a botched hostage rescue attempt by the Navy's SEAL Team Six in 2010 and the accidental bombing of a Medecins Sans Frontieres clinic in Kunduz, Afghanistan in 2015. ${ }^{19}$ These were designed to allow respondents to express preferences in terms of battlefield outcomes and strict performance criteria. Finally, the third treatment group (professionalism) was prompted by news stories that described ethical failures by the military institution, including a 2012 Defense Department report describing the firing of nearly 30 generals and admirals due to offenses ranging from sexual assault to misuse of government funds, and a story discussing the 2009 conviction of several US soldiers accused of the rape and murder of an Iraqi family in $2006{ }^{20}$ This thread was designed to allow respondents to express preferences in terms of professional or ethical standards of conduct.

\footnotetext{
${ }^{19}$ New snippets reflected substantive information from actual news stories. Anthony Faiola, "British aid worker Norgrove killed accidentally by U.S. soldier, inquiry finds", Washington Post Foreign Service, December 3, 2010; Barbara P. Usher, "Kunduz bombing: US attacked MSF clinic 'in error"', BBC News, November 25, 2015.

${ }^{20}$ Craig Whitlock, "Military brass, behaving badly: Files detail a spate of misconduct dogging armed forces", The Washington Post, January 26, 2014; James Dao, "Ex-Soldier Gets Life Sentence for Iraq Murders", The New York Times, May 21, 2009.
} 


\section{Evaluating the Bayesian Hypothesis}

The unique design of this experimental effort in military trust provides a multitude of avenues by which to test the validity of some evaluative bias taking place among partisans. The first explanatory hypothesis I consider is the rational Bayesian account (H2A) in which certain partisans simply possess more prior information about the military institution, making new information comparably weaker in influencing their judgment. The experimental design I employ allows for some investigation of this hypothesis, though observational data is more helpful is assessing its validity. Experimentally, the idea that Republican priors are established on much larger collections of data or high ex ante interest in the subject of military affairs and foreign policy does not find strong support. Among control group respondents, Democrats and Republicans had nearly identical levels of those expressing "high" political interest according to the demographic battery, at $51 \%$ and $50 \%$, respectively. The two partisan groups enjoyed similar distributions in those expressing a high interest in both foreign policy stories and military operation stories in the news, at $59 \%$ and $58 \%$, and among those who indicated just a high interest in the military stories, Democrats outweighed Republicans $71 \%$ to $64 \%$. While these are self-reported statistics about interest in these types of stories and not an objective measure of the respondent's actual understanding of them, they provide a measure of internal validity for the experimental design in that respondents did not express widely different levels of knowledge of the military.

While largely dismissive of $\mathrm{H} 2 \mathrm{~A}$, these results are not altogether surprising. The large panel survey of civil-military attitudes conducted by Schake and Mattis (2016) revealed that while Republicans looked more favorably on the institution's values and were more defensive of its standards and performance, there was not a dramatic separation between partisans in those expressing understanding of the institution itself. In response to the question, "how familiar are you with the U.S. military?", $80 \%$ of Republicans responded with "very familiar" or "somewhat familiar", which while high does not substantially out-pace the $70 \%$ of Independents and $65 \%$ of Democrats who answered in a similar fashion. The argument that Republicans may inform their confidence in the institution based on more direct contact is not wholly without merit. A 2011 Pew Social Trends survey identifies that Republicans (73\%) were more likely than Democrats $(59 \%)$ to have a family member who had served in the military (Golby, Cohn, and Feaver 2016). ${ }^{21}$ However, it is important to note that this pools across all living

\footnotetext{
${ }^{21}$ However, a July 2017 survey by Gallup probed public attitudes specifically among those who expressed "high" confidence in the military; in this group, Republicans who cited "having a friend or family currently serving" or "having served themselves" (24.5\%) as their rationale for expressing such high confidence only slightly outnumbered that community among Democrats $(21.9 \%)$.
} 
Figure 4: Public Confidence in Military Institution by Partisan ID (1980-2017)

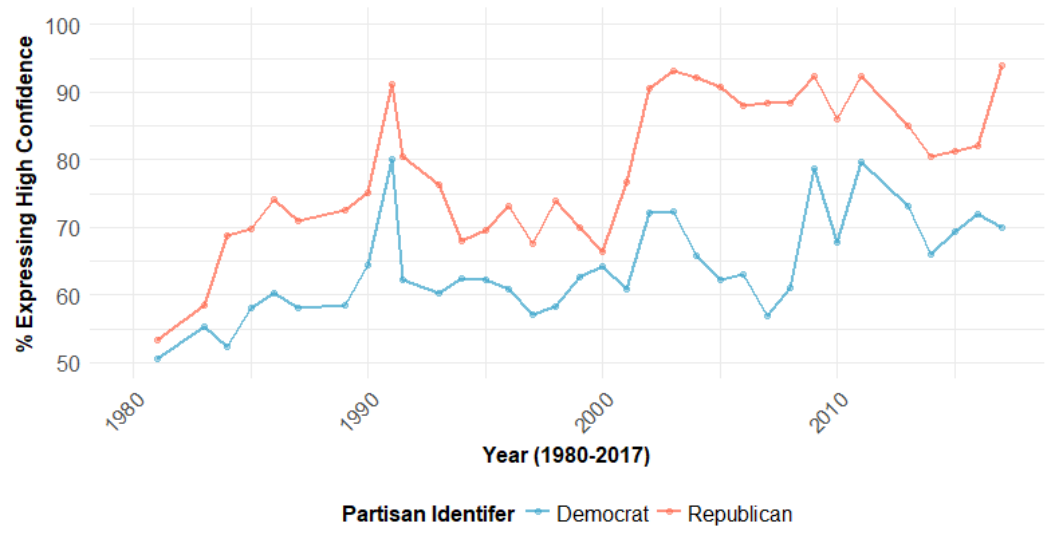

Confidence in Military by Major Party Identification

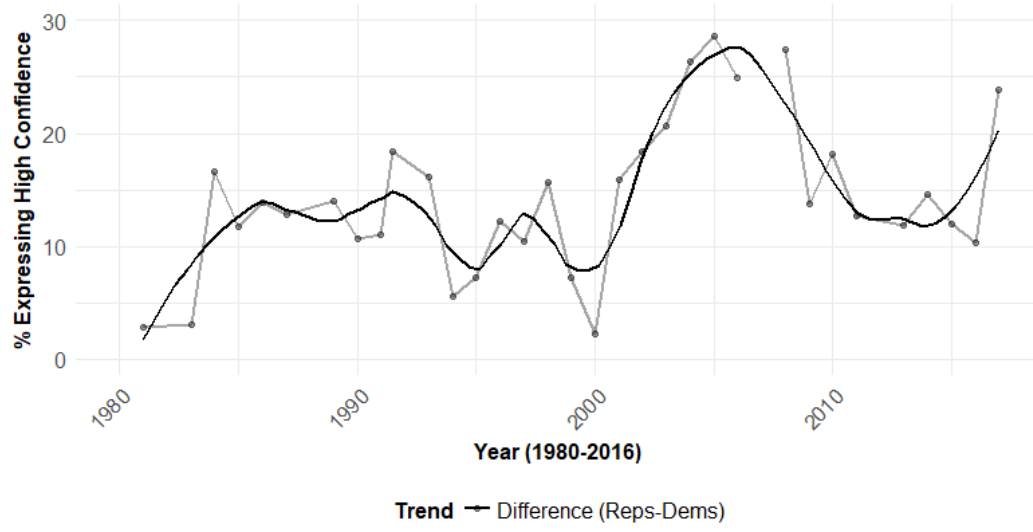

Partisan Gap in Expressed Confidence

NOTE: Figure 5 depicts high expressed confidence in the military institution conditional on stated partisan identity as captured by Gallup June Wave "Confidence in Institutions" survey instrument. "High" confidence categorized as answer of "a great deal" or "quite a lot" to the five-point Gallup question for institutional confidence. LOESS smoother (span =0.3) depicts increasing polarization gap between partisan subgroups for clarity.

veterans; focusing on the more relevant subset of post-9/11 veterans, the Schake/Mattis survey in 2013 found that Republicans and Democrats were comparably likely to have one in their family and far less likely in absolute terms ( $18 \%$ and $12 \%$, respectively).

At a broader level, we have additional reason to doubt the rational process predicted by H2A. While a truly Bayesian process of updating would allow even partisans from opposite ideologies to converge on a common evaluation, this is not a trend we observe in the partisan data for institutional confidence in the military. Figure 4 reveals a similar pattern discussed by Liebert and Golby (2017) through use of 
the Gallup data, in which recently divergent trends - particularly in the high intervention environment post-9/11 - between groups are readily visible. ${ }^{22}$ These non-convergent trends argue against an unbiased process of updating; as Bartels (2002) remarks, "it is quite difficult to produce parallel opinion shifts in a Bayesian framework - unless partisan bias is built into different groups' selection or interpretation of politically relevant information". Not only does partisan confidence in the last several decades occasionally track in this parallel fashion, it widens considerably since the Iraq War, evidence of an inability among partisans to converge on an unbiased assessment of the same institution (Burbach 2017). This presents additional evidence against a completely rational process in that partisans do not update to changing events, information, or shocks in the same way.

\section{Evaluating the Preferences Hypothesis}

However, the nature of this design allows for more specific testing of potential biased updating or the influence of divergent preferences. By varying the nature of newly-salient updating information, we allow partisans to express their preferences in different ways, a flexibility that builds on past empirical efforts (Gaines et al. 2007) and offers an avenue for the counterargument made by Gerber and Green (1999) that a rational process may be at work if partisans simply have different conceptions of what type of military behavior is positive or negative. If $\mathrm{H} 2 \mathrm{~B}$ accurately captures the operant process between partisans, Democrats and Republicans should respond negatively to specific classes of military misconduct. For example, if one partisan group values battlefield effectiveness as a criteria for evaluation, but another places more stock in the professional integrity and organizational practices of the institution, than divergent opinions at the end of the updating process need not come from systematic partisan bias.

Despite this accommodation made by the design, the results indicate a profoundly asymmetric use of the new or newly-salient information among partisans. Figure 5 reveals the change in expressed confidence in the military institution from the control condition by partisan subgroup, assessed using the respondent's identification on the three-point partisan identity scale. While Democratic respondents

\footnotetext{
${ }^{22}$ While Liebert and Golby (2017) observe this trend through analysis of the General Social Survey (GSS) Dataset, I depict this pattern through analysis of the Gallup "Confidence in Institutions" surveys for several reasons. First, regression and factor analyses conducted earlier utilized the Gallup dataset, so I employ it here for continuity. Second, the Gallup survey formulation probes public attitudes about the military institution, while the GSS question asks more specifically about "the people running these institutions"; while the distinction is minimal, I focus on the general impression respondents have of the institution writ large rather than specific figures that may come to mind. Finally, the Gallup formulation of the question uses a five-point scale against the GSS three-point scale, allowing for increased variation in the measured outcome.
} 
Figure 5: Experimental Results (Partisan Breakdown), YouGov - March 2017

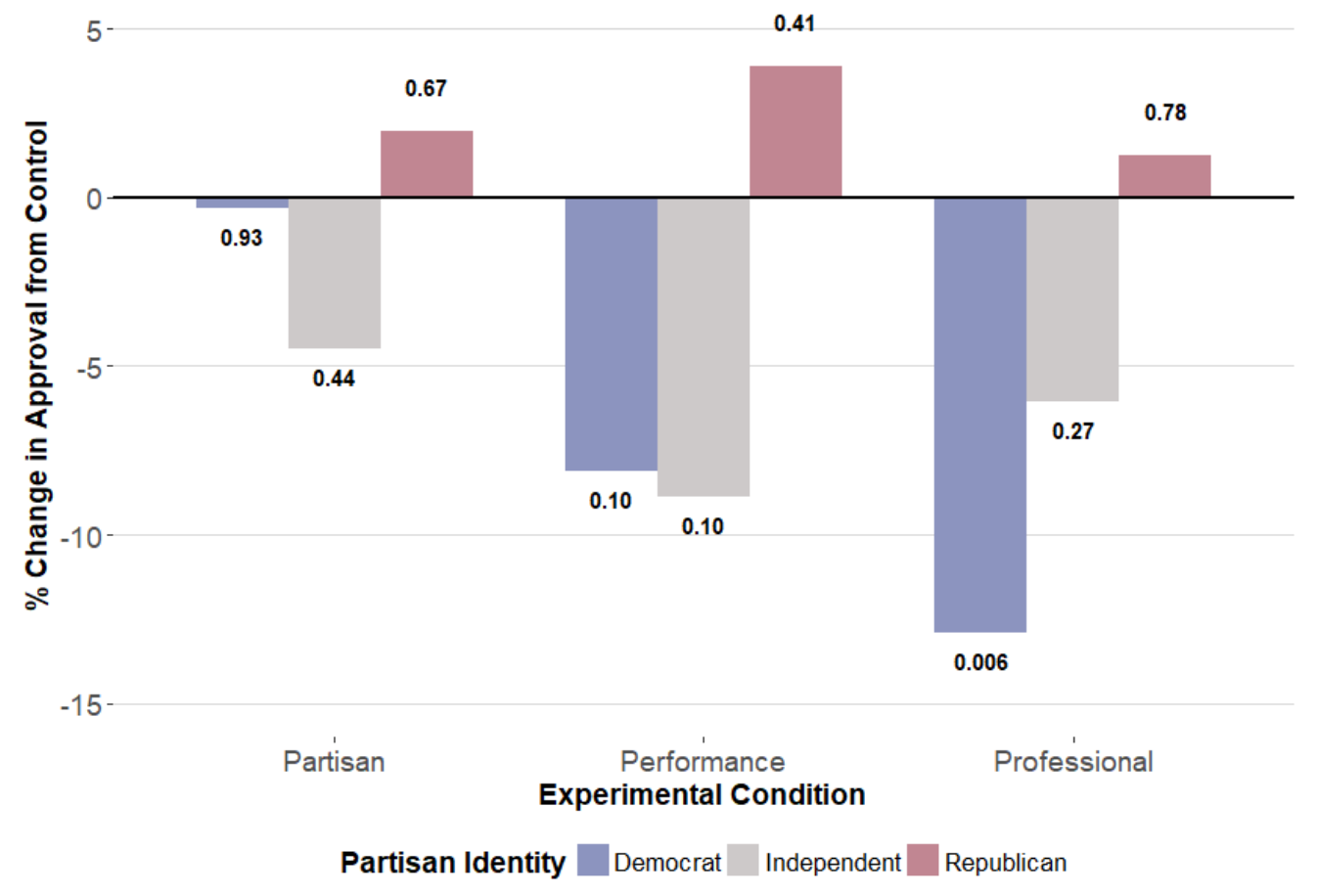

NOTE: This figure depicts deviation in expressed confidence in the military institution as measured by the 11-pt scale in all experimental conditions. Respondent patterns broken down by identification into Democrat, Republican, and Independent subsamples based on self-identification on seven-point partisan identity scale. Reported p-values reflect significance at $95 \%$ level for twotailed t-test for difference in means between experimental and control subgroups. $N_{\text {Total }}=957$

express marginal concern for partisan military activity, they indicate a more defined preference against military performance failures in the tactical setting and professional misconduct, where expressed confidence was reduced by $8 \%$ and $13 \%$, respectively. These results seem to provide empirical replication of the broader fluctuations we observe among Democrats in Figure 4, where confidence in the military institution responds in tandem with the most violent years of the Iraq War and tracks more closely with Independents overall. Specifically, Democrats more closely exhibit the updating sensibilities of non-partisans in their assessment of the military institution, allowing new information to update their evaluations of the armed forces in the expected direction.

Republican response patterns, however, indicate no change in expressed opinion regardless of treatment condition. In all experimental states, Republican changes in confidence for the military institution were positive and statistically insignificant. This also seems to replicate the broader trend observed in 
Figure 4, where Republican confidence patterns seem unmoved by indecisive foreign wars and internal scandals that affected Independent and Democratic levels of trust while stabilizing or increasing Republican levels. Even though the design allows for Republicans to express different preferences from Independents and Democrats, no negative information about the military results in an updated expressed opinion. Attitudes about institutional quality are expected to be quite rigid and difficult to move with such a design; however, the same treatment moved Democrats and Independents in a negative direction to a statistically significant degree, while Republicans remained unaffected. As a result, the unbiased learning process advocated by Gerber and Green (1999) and captured in H2B finds little support with these findings. ${ }^{23}$

The results indicate that Republican respondents had no pronounced predisposition for greater knowledge of the military institution, nor did they adjust their evaluations of the military in response to information about misconduct, despite Democrats and Independents doing so. While offering small support for $\mathrm{H} 2 \mathrm{~A}$ and $\mathrm{H} 2 \mathrm{~B}$, this obliges analysis of the validity of $\mathrm{H} 2 \mathrm{C}$, in which cognitive biases and rationalization steer disconfirmatory information away from critically affecting Republican assessments of the military institution. Whether by blaming military failures on political leaders rather than the armed forces, attributing misconduct to individual failures rather than organizational ones, or downweighting the value of the information because of its contrary narrative, we have strong reason to believe that even with available information, Republican respondents are interpreting information in a far more favorable fashion or polarizing against its substance.

\section{Evidence for Partisan Bias}

The importance of partisan bias to this analysis becomes clearer when analyzing the experimental results among strong partisans. Figure 6 depicts the percentage change in expressed trust and confidence in the military institution from the control condition by sorted partisan groups. Moderate Independents are also included and remain a useful quantitative baseline for the expressed attitudes of individuals with

\footnotetext{
${ }^{23}$ This general response pattern is largely robust to re-classification of respondents according to the five-point ideology scale, with liberals and moderates expressing clear disapproval of professionalism and performance categories and conservatives exhibiting statistically insignificant changes to expressed trust across all conditions. Similar patterns are also visible when re-coding partisan identity based on the seven-point scale, allowing "leaners" to be counted as part of a major party. In this setting, Democrats similarly maintain strong disapproval of both the professionalism and performance conditions and Republicans are similarly unmoved across all conditions. Independents, now classified as those who refused to identify even as a leaner to any party, expressed strong disapproval in the partisan condition (10.4\% loss) and the professional condition (10.9\% loss).
} 
Figure 6: Experimental Results (Strong Partisan Breakdown), YouGov - March 2017

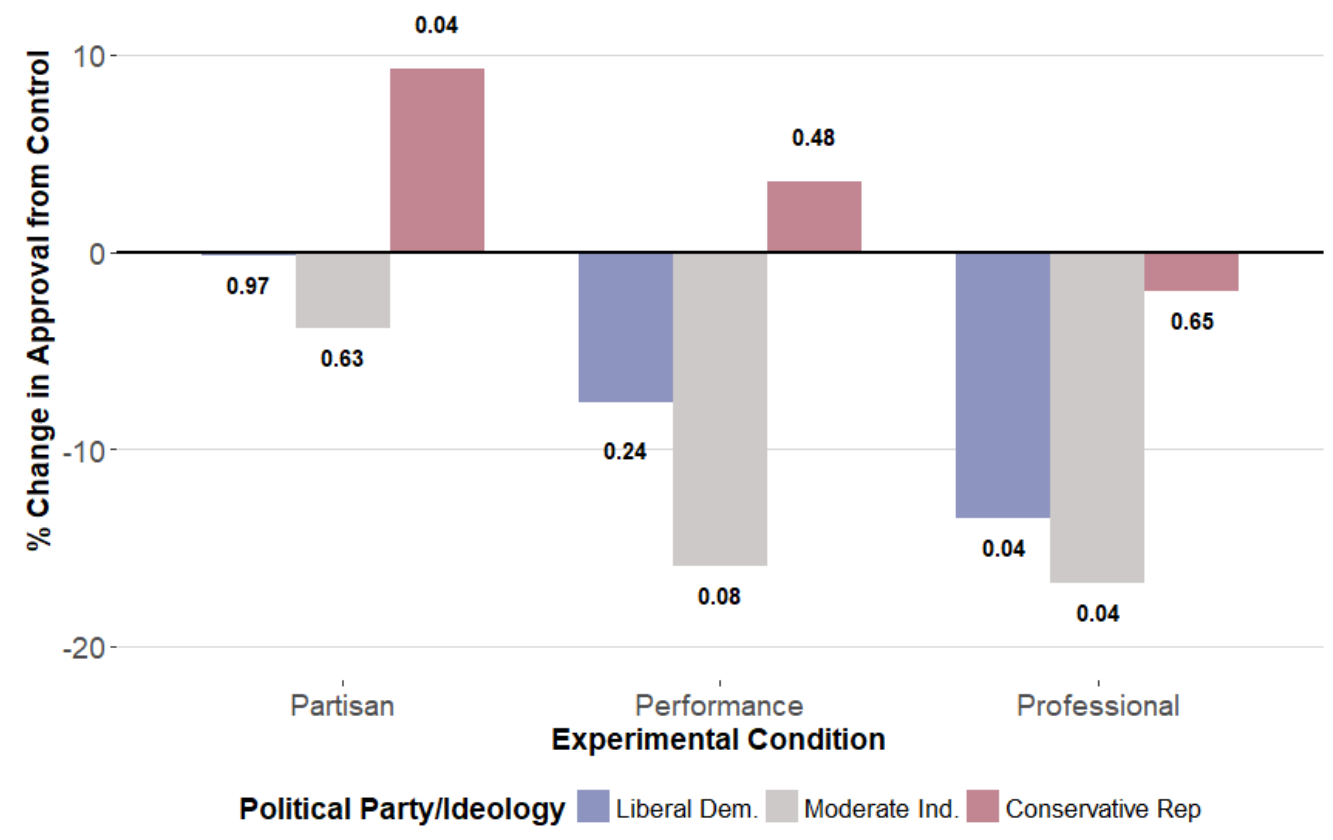

NOTE: This figure depicts deviation in expressed confidence in the military institution as measured by the 11-pt scale in all experimental conditions. Respondent patterns broken down by combined identification into Democrat, Republican, and Independent subsamples based on selfidentification on three-point partisan identity scale and sorted political ideology as conservative, moderate, and liberal on a five-point scale. Reported p-values reflect significance at 95\% level for two-tailed t-test for difference in means between experimental and control subgroups. $N_{\text {Total }}=500$

no incentive for partisan biasing or a desire to minimize dissonance with partisan narratives. At first inspection we observe that sorted Democrats again trend much closer to the attitudes of non-partisans across the different treatment conditions. While similarly unaffected by news of partisan military activity, they express less confidence in the military in response to news of performance failures $(-7.6 \%)$ and far less in response to professional misconduct (-13.4\%). By comparison, moderate Independents expressed similar distaste for battlefield failures (-15.8\%) and ethical or professional scandals $(-16.7 \%)$.

However, closer analysis of strong Republicans reveals a broader polarization than is observable in Figure 5 when pooling across the entire partisan subgroup. In addition to strong Republicans expressing no degradation in their evaluation of the military across treatment conditions, this group responded with a substantively and statistically significant increase in expressed confidence in the institution of nearly 
$10 \%$ in the non-partisan condition. This is particularly surprising given the ostensibly limiting "ceiling effects" one should expect from the conservative Republican control group's mean confidence level of 9.55 on an 11-point scale. This response indicates a defensive polarization away from the expected direction of the treatment and a dramatic departure from the processing that dictated the response of both moderate Independents and liberal Democrats. While these latter groups expressed a clear distaste for certain categories of military behavior, the sorted Republican subgroup actively increased its support for the same institution being evaluated by political out-groups.

These results present strong evidence for the assertions of the partisan bias hypothesis (H2C), that polarizing motivated reasoning is affecting what should be a rational valuation of institutional performance. In addition to Republican responses more broadly exhibiting no negative updating, the response pattern displayed by strong conservative partisans is indicative of a motivated counter-arguing of disconfirming information. This "backfire effect" is a well-documented trend in response to weak issue framing (Chong and Druckman 2007) and among strong ideological partisans, particularly when introduced to negative information about political in-group members (Nyhan and Reifler 2010). Past study on this phenomenon has found that in a "direct challenge to the notion of voters as rational Bayesian updaters", motivated reasoning led individuals to increase support for a favored candidate after receiving negative information about the candidate (Redlawsk 2002). The response patterns exhibited in my experimental results indicate a similar biasing of new information, in an effort to counter-argue "preference-incongruent information and bolster their pre-existing views" (Nyhan and Reifler 2010). It is telling that such a seemingly unexpected increase in strong Republican trust comes in response to information about military support to co-partisan political candidates, further highlighting the central role played by partisan identity in rendering their evaluation. In comparison, such knowledge did not effect strong Democrats or moderate Independents in their evaluation of the military institution.

This response pattern among Republicans is surprising in its reflexive defense of an outside institution, but finds roots within the existing study of affective polarization and its associated biases. Not only has partisan identity been demonstrated to have strong social components that increase animosity regarding political out-groups (Mason 2015, Iyengar and Westwood 2015), but these same mechanisms strengthen the defense of in-group members against disconfirming information, making rational evaluation of institutional quality unlikely (Iyengar, Sood, and Lelkes 2012). The results of this experimental 
design indicate that Republicans have to a certain extent incorporated support for the military institution into the social fabric of their partisan identity, defending it as one would a co-partisan. Their defense of the institution in the face of negative information supports recent study that Republicans are more ideologically coherent (Lelkes and Sniderman 2014) and that such "identity politics" are indeed much stronger among Republicans than other political subgroups due to a lack of cross-cutting identities (Mason and Wronski 2018). As I will discuss later, this level of partisan bias risks compromising the ability of these partisans to objectively evaluate an institution's performance or to properly assess the outcomes of foreign policy ventures.

Additional support for the partisan bias hypothesis (H2C) can be found by examining observational survey data as well, in cases where partisans clearly interpreted a common set of updating information in dramatically different fashions. This process has manifested in a variety of ways, with different effects on expressed confidence in the military institution, as Democrats and political centrists have responded to updating events with far more skepticism than their Republican counterparts when the military is involved. In 2007, the deadliest year for coalition forces in Iraq, public confidence in the military hit its temporary nadir, with $69 \%$ of Americans expressing high confidence in the institution. ${ }^{24}$ Mounting casualties, uncertainty over the success of the "surge" strategy, shifting leadership, and political divisiveness were compounded by decreasing public confidence in the accuracy of battlefield reporting. Between 2003 and 2007, Democratic confidence in the accuracy of battlefield reports from the military dropped from $78 \%$ expressing "a great deal" or "fair amount" to $32 \%$. Republican confidence dropped as well, but three in four still had high confidence in reporting by the military. Instead, Republicans passed their distrust to the press, in whom only $29 \%$ of Republicans expressed high confidence, down from $81 \%$ in 2003. Half of Democrats, by contrast, maintained high confidence in the press reporting from Iraq. ${ }^{25}$ In the midst of growing distrust about the military's wartime performance, Democrats attributed blame to the institution itself, whereas resistant Republicans instead passed blame for inaccuracy to the news media. In addition to highlighting Republican distrust of competing media reports (H1A/B), it also sheds light on how updating information was rationalized to support a prior rather than influence an updated evaluation (H2C).

When military misconduct and accusations of large-scale sexual assault problems within the insti-

\footnotetext{
${ }^{24}$ Gallup, "Confidence in Institutions, June Wave Survey", 2007

${ }^{25}$ The Pew Research Center for the People and the Press, "Little Confidence in Military or Press Depictions of Iraq", April 5, 2007.
} 
tution peaked in 2013, partisans again split over the nature of the problem and its proposed solutions. While half of Democrats directly attributed the reports of sexual assault to "underlying problems with military culture", nearly $70 \%$ of Republicans ascribed the incidents to individual acts of misconduct detached from the institution as a whole. When considering the best way of handling the problem, $58 \%$ of Democrats stated that Congress needed to directly intervene to change military law or strip military commanders of their legal authority. In contrast, a similar percentage of Republicans believed that the military should be left to handle the problem internally without outside interference. ${ }^{26}$ Again, with partisans given similar information about negative military activity, these groups interpret and employ that information is widely different ways. Conditional on both subgroups believing the factual nature of the information, Democrats negatively updated their evaluation against the military institution, whereas Republicans drew fundamentally different interpretations that insulated the institution from more direct criticism.

These cases lend additional credence to the validity of $\mathrm{H} 2 \mathrm{C}$, that biased interpretations driven by partisan sentiment lead Republicans to draw systemically more friendly interpretations from the same information about the military, when that information is substantively negative, compared to Democrats and Independents. Though not decisively inferential, examination of the cognitive resources expended by partisans on either side can inform our understanding of the mental process at work. Taber and Lodge (2006) argue that the sort of disconfirmation bias predicted by $\mathrm{H} 2 \mathrm{C}$ could manifest in those respondents taking "more time processing counter-attitudinal arguments than pro-attitudinal arguments, [...] to spend the extra time denigrating, deprecating, and counter-arguing the incongruent arguments". Across treatment groups, we observe these patterns in a similar fashion. Non-partisan group Democrats and Republicans spent almost the same amount of time completing the survey; this is unsurprising as this experimental condition was where partisans actually expressed similar attitudes. However, Republican respondents in the professionalism and performance conditions spent on average nearly 20-25\% more time completing the survey than their Democrat counterparts. ${ }^{27}$ Again, though not conclusive in its own right, further study should examine this causal pathway more closely.

\footnotetext{
${ }^{26}$ Pew Research Center/Washington Post Survey, "Sexual Assault in the Military Widely Seen as Important Issues, But No Agreement on Solution", June 12, 2013.

${ }^{27}$ After removing outliers who took more than 1000 seconds to complete the survey, I found that Republicans and Democrats in the non-partisan condition spent approximately 83 and 86 seconds on the survey instrument, respectively. In the professionalism condition, the same subgroups spent approximately 84 and 100 seconds, respectively, and 76 and 97 seconds, respectively, in the performance condition. The amounts to a $19 \%$ increase in Republican time expenditure in the former and a $27 \%$ increase in the latter.
} 
Collectively, both this complementary data and the results of the experiment promote strong support for a cognitive bias born of partisan affiliation when interpreting information regarding the military institution. While political liberals and centrists seem to utilize new or newly-salient information in the expected fashion, updating their opinions of the organization based on knowledge of negative actions or behavior, conservatives seem to defend the institution as they would an extension of their own political party. Given the apolitical nature of the military, this is particularly puzzling and potentially dangerous. If conservative confidence in military elites is seen by politicians to be highly durable, the latter may increase appeals to the military as a political device for electoral gains or policy support, bringing the military institution closer into the political fold and risking a dangerous erosion of civil-military balance.

\section{Discussion}

The results of both of my observational and experimental design strategies generate several points for discussion. What are the implications of these empirical findings? As I have stated, neither Republican favor for the military establishment at the elite level, nor popular military identification with the Republican party are particularly novel concepts. However, this analysis makes the case for a complementary and dynamic process in which partisan Republicans in society are less likely to accurately evaluate the military institution based on its conduct. The core of institutionalist theory envisions that citizens continually update their evaluations of social and political institutions, rewarding positive performers and pressuring negative ones to reform and improve. However, these results indicate that the military may benefit from a nearly unconditional deference from targeted partisans. I organize the principal findings of this analysis and briefly discuss their potential implications.

First, these findings suggest that both polarization over military credibility and military politicization will likely continue into the future. The principal findings of my analysis include (1) the wide variation in reporting on military conduct and performance across media outlets and (2) that even when offered the opportunity to express expectations of military conduct differently, Republicans display a biased processing reflective of political in-group members. The lack of response to new or newly-salient information displayed by this group in my experimental framework mirrors both the aggregate confidence trends we observe over time and the sensibilities of a literature in partisan resistance and "perceptual screening" in which contrary information is more easily dismissed for challenging prior beliefs (Camp- 
bell et al. 1980 Zaller 1992, Gerber and Green 1999). One implication of these findings is that both information exposure and partisan bias in evaluating the military interact to collectively solidify this polarization between partisans: if a subset of society is less likely to receive contrary information, it is less cognitively costly to dismiss the residual information or for the news to create a "backfire effect", even if that information is useful to an informed evaluation. Consistent exposure to positively-framed or under-reported information on military failures could perpetuate this inaccurate prior among partisans, particularly strong Republicans, making new information less likely to update their evaluations.

The fact that strong Republicans in this analysis exhibit a seemingly partisan bias in defense of an apolitical institution is particularly curious and potentially damaging to preserving the non-partisanship of the military. Both the experimental results and observational survey data on military failures have shown Republicans are more likely to consider military misconduct a product of individual actors rather than large organizational flaws. These defensive patterns reflect a political tribalism among Republicans with respect to the military, conforming to patterns of in-group favoritism and partisan biases (Hewstone, Rubin, and Willis 2002 Iyengar and Westwood 2015). When confronted with the prospect of inaccurate information coming from the battlefield, Republicans were far more likely to blame the news media, while Democrats and Independents more directly charged the military itself. It is telling that just as military confidence has been consistently high among Republicans, an equivalent pattern is found among Democrats for the mass media. ${ }^{28}$ Though it may be overly simplistic to ascribe partisan affiliations to either institution writ large, Republican distrust in a liberal-favored institution like the mass media has the dual effect of discrediting new information and striking at a perceived partisan opponent. As such, Republican trust in the military would not be a purely rational valuation, but rather an expression of partisan attitudes. Collectively, these patterns provide strong reasons to suspect that the partisan "gap" in confidence is likely to continue.

Second, a reflexive defense of the military institution from criticism can prevent not only an objective evaluation of that institution's quality, but of foreign policy ventures in which the military is a principal actor. In-group defensiveness not only insulates the military from direct criticism, but also re-directs blame for the outcomes of military intervention to other sources. Recent polling on public attitudes

\footnotetext{
${ }^{28}$ Democratic trust in the mass media has remaining consistently high since 2001 , with a nadir of $51 \%$ expressing "a great deal" or "fair amount" in 2016; however, Democrats expressed more traditionally high levels of trust in the media in 2017 at $72 \%$, as Republican trust cratered to $14 \%$ in the same year. Art Swift, "Democrats' Confidence in Mass Media Rises Sharply From 2016", Gallup, September 21, 2017.
} 
about ongoing US military interventions has revealed that a plurality of individuals believe that civilian decision-making is to blame for a lack of strategic victory, rather than military incompetence (Schake and Mattis 2016). Partisan defense of the military institution risks compounding the problem that polarization over foreign policy already presents; namely, that partisans will base their impressions of war outcomes on inaccurate information (Berinsky 2009) or partisan narratives (Gaines et al. 2007), as evidenced by previous study on the Iraq War.

If civilian leaders are sensitive to public attitudes on the merits of military interventions, this type of biased processing compromises the ability of the public to effectively learn the proper lessons of select foreign policy ventures and aggregate them into effective choices. The inability to concede when outgroup partisans are successful - or in this case, when in-group members fail - has been advocated by some scholars as another product of polarization (Iyengar, Sood, and Lelkes 2012). As Schultz (2018) argues, this is one of the principal challenges of polarization's intersection with foreign policy: more than any time in recent US history, wars are seen as the extension of a specific party's agenda rather than a national effort. The incorporation of military interventions into a partisan dialogue may therefore "impede the country's collective ability to learn and adapt from foreign policy failures." If partisan biases already threaten the ability of the public to objectively evaluate war outcomes, a subjective defense of the military institution from criticism compounds this problem.

The third dimension I consider is the potentially damaging influence of this partisan incorporation of high military trust on the stability of US civil-military relations. The maintenance of a non-partisan and apolitical military is a foundational characteristic of a functioning democracy where civilian control of the armed forces is assured. Furthermore, a broad consensus across civil-military relations scholars concludes that continued military interference into the political sphere will damage institutional credibility among the public and weaken the voices of active-duty officers seeking to responsibly advise civilian leaders (Golby 2011, Liebert and Golby 2017; Dempsey 2009, Urben 2010). However, a military institution with perceptibly rigid levels of appeal to a subset of the public could become an increasingly politicized instrument in partisan debates through several mechanisms.

First, political leaders may be tempted to continue to incorporate military elites into the political debate in an attempt to leverage high credibility with their audience. Prominent endorsements from 
military elites for political candidates, though they have been found ineffective in absolute terms (Golby, Dropp, and Feaver 2012), have become increasingly frequent across both parties. Military appointments to posts typically occupied by civilian experts have also increased across both parties. Though highprofile ex-military appointments are not new, the Trump administration placed such figures closer to the political functions of the executive branch. The installment of recently-retired James Mattis as Secretary of Defense met with consternation from political opponents concerned about the preservation of civilian control of the military. ${ }^{29}$ The elevation of John Kelly to the post of White House Chief of Staff was similarly admonished by civil-military scholars on the grounds that "having a retired general serve in such an unabashedly partisan role further blurs the boundaries between the military and politics, and erodes the long-standing reputation of the U.S. military as an apolitical institution" 30 The result has been an increasing discussion on the emergence of a "tipping point" in American confidence in the military. ${ }^{31}$ Yet the principal utility for politicians in such appointments comes from the clout of the military institution with a public audience. The desire to utilize highly-trusted military elites as a source of public-facing credibility may be irresistible to political elites cognizant of the seemingly unconditional trust their audience places in such figures.

Second, a more politically-active military is inherently problematic for traditional theories of stable civil-military relations. If military elites are continually sought out for incorporation into a partisan political agenda, military leaders themselves may recognize their position with the conservative public as irrevocably durable and embolden them to intervene more in the political sphere. Remarking on the military's seemingly immovable trust with the public, former Chairman of the Joint Chiefs of Staff Martin Dempsey remarked in 2011 that, "maybe if I knew what it would take to screw it up, I could avoid it" 32 This wide latitude with the public, specifically the subset of political conservatives, combined with an increasingly political role for the military, is likely to create strong incentives for an activist military institution that leverages its clout with the public as a means for securing its own policy preferences. While Dempsey (2009) argues that a "paradox of prestige" will incrementally damage military credibility with each new foray into the political debate, a high level of trust in the military among

\footnotetext{
${ }^{29}$ Rebecca Shabad, "How unusual is Trump's Cabinet of generals?", CBS News, December 9, 2016.

${ }^{30}$ David Barno and Nora Bensahel, "Why No General Should Serve as White House Chief of Staff", War on the Rocks, September 12, 2017.

${ }^{31}$ Daniel Drezner, "Is this the tipping point for trust in the U.S. military?", The Washington Post, October $26,2017$. Drezner remarks on the 2017 Gallup data directly, saying that "[s] eventy-two percent of trust is pretty high. But it is worth noting that this number was 82 percent a decade ago. I am beginning to wonder if Trump's elevation of the military to such a high-profile role risks the reputation of the armed forces."

${ }^{32}$ Quoted in Jim Gourley, "Where is the Tipping Point for Trust in America's Military? And are we near it?" Foreign Policy, February 14, 2014.
} 
Republicans - crystallized by biased processing and limited information exposure - could render that process inert. The result is a potentially damaging and reciprocal process of political leaders designing a more partisan role for military elites, who in turn use that placement for agenda-setting or partisan activity of their own.

The central claim of this analysis is that political polarization in institutional confidence for the military cannot be explained solely by a baseline difference in preferences across parties, but must account for dynamic processes of updating and re-evaluation. Partisans on both sides have neither converged on a common understanding of the institution's quality - the only true "rational" process according to Bartels (2002) - nor have they responded in parallel during wartime or other key shocks. Instead, the divergence in partisan confidence in the armed forces indicates a fundamentally different evaluation process between these groups. However, as I summarize here, it is equally important to understand the negative externalities of polarization in this domain. A large segment of the public observes the military as a credible voice in the political debate, especially with regards to the prospect of military intervention ${ }^{33}$ Such an unconditional trust in the institution to provide credible information, as traditional expert communities have been increasingly discredited, can have potentially negative ramifications for the preservation of an apolitical military.

\section{Conclusion}

Elite communities perform an essential function in democratic society, providing the public with information about the functioning of government and cues for opinion-formation on complex policy. In an environment of increasing skepticism for traditional social and policy elites, the process by which individuals choose to select and trust specific elite sources in the political discourse is of great importance. As the most respected and trusted institution in American society, the military factors prominently into the discussion regarding elite source credibility; however, theoretical and empirical efforts to explain differences in public trust in that institution among different political subgroups have been limited in scope. Indeed, aggregate trust and confidence figures, usually referenced as indicative of broad public support for the military's performance, conceal an underlying polarization in which different partisans observe information about an institution in society and yet render different levels of expressed confidence

\footnotetext{
${ }^{33}$ Scott Clement and Philip Rucker, "Poll: Far more trust generals than Trump on N. Korea, while two-thirds oppose preemptive strike", The Washington Post, September 24, 2017.
} 
in that organization.

This analysis has contributed to the broader bodies of study in civil-military relations, elite credibility, political polarization, and institutional confidence by proposing a potential cause of polarization in expressed trust for the military as a dynamic process. While a considerable literature has utilized elitelevel policy preferences or mass politicization as an explanation for Republican-military proximity, this does not explain why polarization would persist or even intensify, particularly during periods of wartime without a decisive victory. I argue that a dynamic theory of evaluative updating helps to complete this picture. Using text-data and observational data on reporting trends, I have demonstrated that during a key period in the Iraq war, conservative media consumers were much less likely to be exposed to useful updating information about military performance, misconduct, or scandals. When these stories were reported, they were often framed in such a way that minimized direct criticism to the institution or to draw attention away from the costliness of war. With the persistent effect of media "echo-chambers" in the modern information environment, there is little reason to believe this trend will end into the future.

Even if information regarding military misconduct or failures is directly provided to individuals, my experimental design reveals that Republicans, particularly strong or "sorted" ones, are far more resistant to this new or newly-salient information. While liberals and moderates express clear preferences for military behavior - losing more confidence in response to professional misconduct or performance failures - conservatives are almost uniformly undeterred. I find that this is less likely to be the result of a rational updating process, better-informed priors, or divergent preferences, and more likely to be the result of biased evaluative processes, in-group affective polarization, and motivated partisan reasoning. Limited information exposure makes contrary information cognitively easier to dismiss; however, there is also evidence of the type of partisan bias and "backfire" attitude polarization that indicates Republicans see the military as an extension of their political in-group.

As I have discussed, the negative ramifications of unconditional trust in the military are self-evident: reflexive insulation of the military institution from criticism risks compromising the public's ability to effectively judge its performance and the merits of foreign policy outcomes. Furthermore, political elites seeking to leverage the reflected credibility of the military may pull that institution into the partisan debate with increased frequency. Though many civil-military scholars have stressed that restraint among 
military elites from political interference is necessary for the preservation of an apolitical military, it is also contingent upon a similar restraint among political elites not to incorporate such interference into partisan strategies. Further study into the processes by which individuals in society choose credible elites requires increased focus on the military, especially as active and retired officers play an increasingly central role in the political discussion. 


\section{References}

Abramowitz, Alan I. and Kyle L. Saunders (2008). "Is Polarization a Myth?" In: The Journal of Politics 70.2 , pp. $542-555$.

Achen, Christopher H. (1992). "Social psychology, demographic variables, and linear regression: Breaking the iron triangle in voting research". In: Political behavior 14.3, pp. 195-211.

Achen, Christopher H. and Larry M. Bartels (2017). Democracy for Realists: Why Elections Do Not Produce Responsive Government. Revised ed. edition. S.l.: Princeton University Press. 408 pp.

Bafumi, Joseph and Robert Y. Shapiro (2009). "A New Partisan Voter". In: The Journal of Politics 71.1, pp. 1-24.

Bartels, Larry M. (2002). "Beyond the Running Tally: Partisan Bias in Political Perceptions". In: Political Behavior 24.2, pp. 117-150.

Baum, Matthew A. and Tim J. Groeling (2009). "Shot by the Messenger: Partisan Cues and Public Opinion Regarding National Security and War". In: Political Behavior 31.2, pp. 157-186.

Berinsky, Adam J. (2007). "Assuming the costs of war: Events, elites, and American public support for military conflict". In: The Journal of Politics 69.4, pp. 975-997.

- (2009). In Time of War: Understanding American Public Opinion from World War II to Iraq. 1 edition. Chicago: University Of Chicago Press. 360 pp.

Blei, David M., Andrew Y. Ng, and Michael I. Jordan (2003). "Latent dirichlet allocation". In: Journal of machine Learning research 3 (Jan), pp. 993-1022.

Brady, Henry E. and Paul M. Sniderman (1985). "Attitude Attribution: A Group Basis for Political Reasoning". In: American Political Science Review 79.4, pp. 1061-1078.

Burbach, David T. (2017). "Gaining Trust While Losing Wars: Confidence in the U.S. Military after Iraq and Afghanistan". In: Orbis 61.2, pp. 154-171.

- (2019). "Partisan Dimensions of Confidence in the U.S. Military, 1973-2016". In: Armed Forces \&3 Society 45.2, pp. 211-233.

Campbell, Angus et al. (1980). The American Voter. Chicago Ill.: University Of Chicago Press. 576 pp.

Chong, Dennis and James N. Druckman (2007). "A Theory of Framing and Opinion Formation in Competitive Elite Environments". In: Journal of Communication 57.1, pp. 99-118.

Citrin, Jack (1974). "Comment: The Political Relevance of Trust in Government." In: American Political Science Review 68.3, pp. 973-988. 
Dempsey, Jason K. (2009). Our Army: Soldiers, Politics, and American Civil-Military Relations. Princeton: Princeton University Press. 280 pp.

Desch, Michael C. (2001). "Explaining the Gap: Vietnam, the Republicanization of the South, and the End of the Mass Army". In: Feaver, Peter D. and Richard H. Kohn. Soldiers and Civilians: The Civil-Military Gap and American National Security. Cambridge, Mass: MIT Press.

Downs, Anthony (1957). An Economic Theory of Democracy. 1st edition. Boston: Harper and Row. 310 pp.

Feaver, Peter D. (1999). "Civil-military relations". In: Annual Review of Political Science 2.1, pp. 211241.

Feaver, Peter D. and Richard H. Kohn, eds. (2001). Soldiers and Civilians. 1st edition. Cambridge, Mass: The MIT Press. 550 pp.

Feldman, Stanley, Leonie Huddy, and George E. Marcus (2015). Going to War in Iraq: When Citizens and the Press Matter. Reprint edition. Chicago: University Of Chicago Press. 248 pp.

Foa, Roberto Stefan and Yascha Mounk (2016). "The democratic disconnect". In: Journal of Democracy 27.3 , pp. $5-17$.

Gaines, Brian J. et al. (2007). "Same facts, different interpretations: Partisan motivation and opinion on Iraq". In: The Journal of Politics 69.4, pp. 957-974.

Garb, Maja and Marjan Malesic (2016). "The causes of trust and distrust in the military". In: Defense 85 Security Analysis 32.1, pp. 64-78.

Gerber, Alan and Donald Green (1999). "Misperceptions about perceptual bias". In: Annual review of political science 2.1, pp. 189-210.

Gilens, Martin (2001). "Political Ignorance and Collective Policy Preferences". In: American Political Science Review 95.2, pp. 379-396.

Golby, James (2011). "Duty, Honor... Party? Ideology, Institutions, and the Use of Military Force". $\mathrm{PhD}$ thesis. Stanford University.

Golby, James, Lindsay Cohn, and Peter D. Feaver (2016). "Thanks for Your Service: Civilian and Veteran Attitudes after Fifteen Years of War". In: Schake, Kori N. and Jim Mattis. Warriors and Citizens: American Views of Our Military. Stanford, Calif.: Hoover Institution Press, pp. 69-96.

Golby, James, Kyle Dropp, and Peter D. Feaver (2012). Military Campaigns: Veterans' Endorsements and Presidential Elections. Center for a New American Security. 
Golby, James, Peter D. Feaver, and Kyle Dropp (2017). "Elite Military Cues and Public Opinion About the Use of Military Force". In: Armed Forces 83 Society 44.1, p. $0095327 X 1668706$.

Gronke, Paul and Peter D. Feaver (2001). "Uncertain Confidence: Civilian and Military Attitudes and Civil-Military Relations". In: Soldiers and Civilians: The Civil-Military Gap and American National Security. Ed. by Richard H. Kohn and Peter D. Feaver. MIT Press.

Hanitzsch, Thomas and Rosa Berganza (2012). "Explaining Journalists' Trust in Public Institutions Across 20 Countries: Media Freedom, Corruption, and Ownership Matter Most: Explaining Journalists' Public Trust". In: Journal of Communication 62.5, pp. 794-814.

Hetherington, Marc (1998). "The Political Relevance of Political Trust". In: American Political Science Review 92.4, pp. 791-808.

Hetherington, Marc and Elizabeth Suhay (2011). "Authoritarianism, Threat, and Americans Support for the War on Terror". In: American Journal of Political Science 55.3, pp. 546-560.

Hewstone, Miles, Mark Rubin, and Hazel Willis (2002). "Intergroup Bias". In: Annual Review of Psychology 53, pp. 575-604.

Hill, Andrew A., Leonard Wong, and Stephen J. Gerras (2013). "Self-Interest Well Understood: The Origins \& Lessons of Public Confidence in the Military". In: Daedalus 142.2, pp. 49-64.

Holsti, Ole R. (1998). "A Widening Gap between the U.S. Military and Civilian Society?: Some Evidence, 1976-96". In: International Security 23.3, p. 5.

Huddy, Leonie, Lilliana Mason, and Lene Aaroe (2015). "Expressive Partisanship: Campaign Involvement, Political Emotion, and Partisan Identity". In: American Political Science Review 109.1, pp. 117.

Huntington, Samuel P. (1957). The Soldier and the State: The Theory and Politics of Civil-Military Relations. Cambridge: Belknap Press. 560 pp.

Iyengar, Shanto and Kyu S Hahn (2009). "Red Media, Blue Media: Evidence of Ideological Selectivity in Media Use". In: Journal of Communication 59.1, pp. 19-39.

Iyengar, Shanto and Donald R. Kinder (1989). News That Matters: Television and American Opinion, Updated Edition. Updated ed. edition. Chicago: University Of Chicago Press. 216 pp.

Iyengar, Shanto, Gaurav Sood, and Yphtach Lelkes (2012). "Affect, Not Ideology". In: Public Opinion Quarterly 76.3, pp. 405-431.

Iyengar, Shanto and Sean J. Westwood (2015). "Fear and Loathing across Party Lines: New Evidence on Group Polarization". In: American Journal of Political Science 59.3, pp. 690-707. 
Jamieson, Kathleen and Joseph Cappella (2008). Echo chamber: Rush Limbaugh and the conservative media establishment. Oxford University Press.

King, David C. and Zachary Karabell (2002). "The Generation of Trust". In: Washington DC: AEI.

Kohn, Richard H. (1994). "Out of control: The crisis in civil-military relations". In: The national interest 35, pp. 3-17.

- (2002). "The erosion of civilian control of the military in the United States today". In: Naval War College Review 55.3, p. 9.

Kohn, Richard H. et al. (1994). "An Exchange on Civil-Military Relations". In: The National Interest 36 , pp. $23-31$.

Ladd, Jonathan McDonald (2010). "The Neglected Power of Elite Opinion Leadership to Produce Antipathy Toward the News Media: Evidence from a Survey Experiment”. In: Political Behavior 32.1, pp. 29-50.

Lelkes, Yphtach and Paul M. Sniderman (2014). "The Ideological Asymmetry of the American Party System". In: British Journal of Political Science 46, pp. 825-844.

- (2016). "The Ideological Asymmetry of the American Party System". In: British Journal of Political Science 46.4, pp. 825-844.

Liebert, Hugh and James Golby (2017). "Midlife Crisis? The All-Volunteer Force at 40". In: Armed Forces 8 Society 43.1, pp. 115-138.

Lipset, Seymour Martin and William Schneider (1983). "The Decline of Confidence in American Institutions". In: Political Science Quarterly 98.3, p. 379.

Lupia, Arthur and Mathew D. McCubbins (1998). The Democratic Dilemma: Can Citizens Learn What They Need to Know? Cambridge, U.K. ; New York: Cambridge University Press. 300 pp.

Mason, Lilliana (2015). "“I Disrespectfully Agree”: The Differential Effects of Partisan Sorting on Social and Issue Polarization: PARTISAN SORTING AND POLARIZATION". In: American Journal of Political Science 59.1, pp. 128-145.

Mason, Lilliana and Julie Wronski (2018). "One Tribe to Bind Them All: How Out Social Group Attachments Strengthen Partisanship". In: Advances in Political Psychology 39.1, pp. 257-277.

Miller, Arthur (1974). "Political Issues and Trust in Government: 1964-1970". In: American Political Science Review 68.3, pp. 951-972.

Mishler, William and Richard Rose (2001). "What are the origins of political trust? Testing institutional and cultural theories in post-communist societies". In: Comparative political studies 34.1, pp. 30-62. 
Newton, Ken and Pippa Norris (2000). "Confidence in public institutions". In: Disaffected democracies. What's troubling the trilateral countries.

Nye, Joseph (1997). "The media and declining confidence in government". In: Harvard International Journal of Press/Politics 2.3, pp. 4-9.

Nyhan, Brendan and Jason Reifler (2010). "When Corrections Fail: The Persistence of Political Misperceptions". In: Political Behavior 32.2, pp. 303-330.

Petty, Richard E. and John T. Cacioppo (1986). Communication and Persuasion: Central and Peripheral Routes to Attitude Change. Springer. 264 pp.

Pharr, Susan J, Robert D. Putnam, and Russell J Dalton (2000). "A Quarter-Century of Declining Confidence". In: Journal of Democracy 11.2, pp. 5-25.

Post, Abigail and T. S. Sechser (2016). "Hidden Norms in International Relations: Public Opinion and the Use of Nuclear Weapons". In: Annual Meeting of Peace Science Society. University of Notre Dame, South Bend, IN.

Redlawsk, David P. (2002). "Hot Cognition or Cool Consideration? Testing the Effects of Motivated Reasoning on Political Decision Making". In: The Journal of Politics 64.4, pp. 1021-1044.

Roberts, Margaret E., Brandon M. Stewart, and Dustin Tingley (2014). stm: R package for Structural Topic Models.

Rothstein, Bo and Dietlind Stolle (2007). "The quality of government and social capital: a theory of political institutions and generalized trust". In: QoG Working paper series 2.

Schake, Kori N. and Jim Mattis, eds. (2016). Warriors and Citizens: American Views of Our Military. Stanford, California: Hoover Institution Press. 360 pp.

Schultz, Kenneth A. (2018). "Perils of Polarization for U.S. Foreign Policy". In: The Washington Quarterly 40.4, pp. 7-28.

Sidman, Andrew H. and Helmut Norpoth (2012). "Fighting to win: Wartime morale in the American public". In: Electoral Studies 31.2, pp. 330-341.

Stroud, Natalie (2008). "Media Use and Political Predispositions: Revisiting the Concept of Selective Exposure". In: Political Behavior 30.3, pp. 556-576.

Taber, Charles S. and Milton Lodge (2006). "Motivated skepticism in the evaluation of political beliefs". In: American Journal of Political Science 50.3, pp. 755-769. 
Taylor, S. E. and Susan Fiske (1978). "Salience, attention, and attribution: Top of the head phenomena". In: Advances in experimental social psychology. Vol. 11. New York, NY: Academic Press, pp. 249288.

Urben, Heidi (2010). "Civil-Military Relations in a Time of War". PhD thesis. Georgetown University.

Wiegand, Krista E. and David L. Paletz (2001). "The Elite Media and the Military-Civilian Culture Gap". In: Armed Forces 83 Society 27.2, pp. 183-204.

Williams, John T. (1985). "Systemic influences on political trust: The importance of perceived institutional performance". In: Political Methodology, pp. 125-142.

Wittkopf, Eugene R. (1990). Faces of Internationalism: Public Opinion and American Foreign Policy. Durham: Duke University Press Books. 414 pp.

Yang, Kaifeng and Marc Holzer (2006). "The performance-trust link: Implications for performance measurement". In: Public Administration Review 66.1, pp. 114-126.

Zaller, John R. (1992). The Nature and Origins of Mass Opinion. Cambridge University Press.

Zaller, John R. and Stanley Feldman (1992). "A Simple Theory of the Survey Response: Answering Questions versus Revealing Preferences". In: American Journal of Political Science 36.3, pp. 579616. 


\section{A Appendix A: Covariate Balance and Regression Results}

\section{A.1 Confidence in US Institutions}

Figure A.7: Public Confidence in US Institutions (1973-2016)

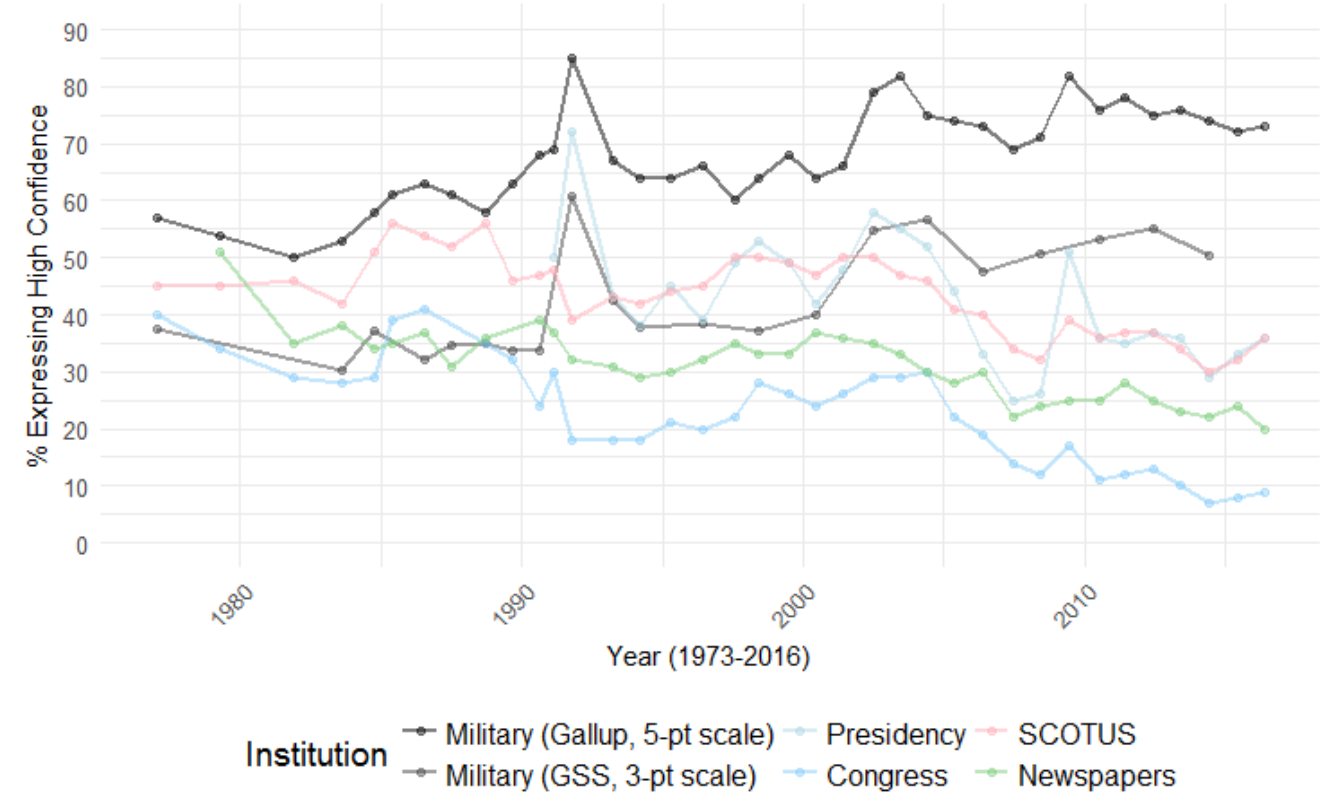

NOTE: Figure A.7 depicts aggregate levels of public confidence in institutions as measured by Gallup "Confidence in Institutions" annual survey; additional information on military confidence comes from General Social Survey (GSS). Note: Gallup collection on Presidency confidence did not begin until 1991 survey fieldings. 
Figure A.8: Principal Component Analysis of Institutional Feeling Thermometer Ratings, ANES (2012)
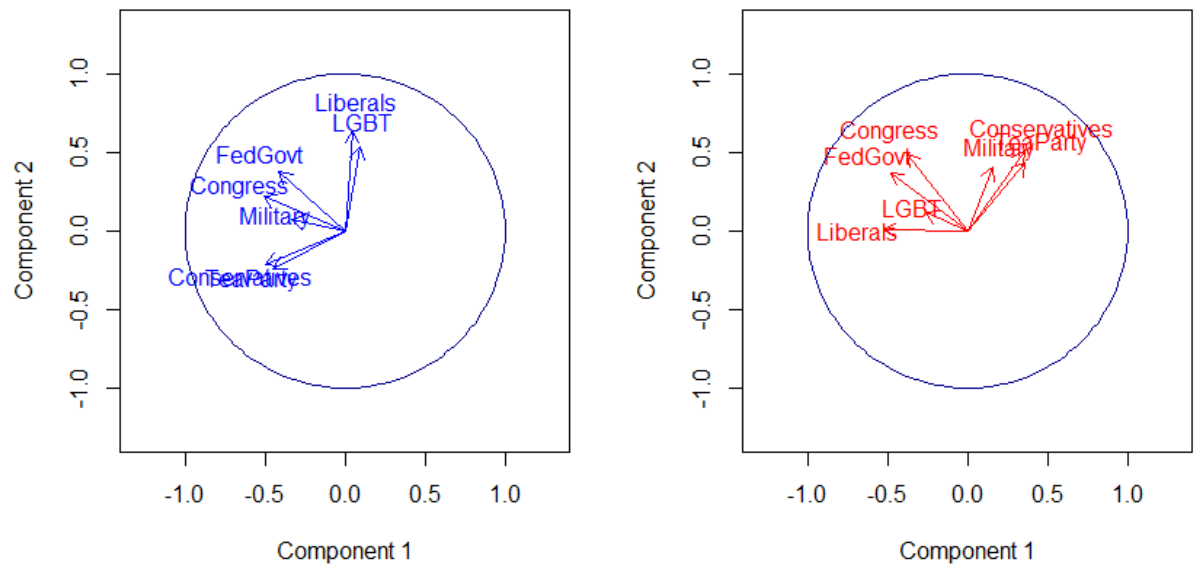

NOTE: Figure A.8 depicts the results of principal component analysis (PCA) on the feeling thermometer scores for several institutions in US society according to the 2012 ANES, broken down by partisan subgroups. First two principal components depicted for clarity. Unit circle denotes maximum value of factor loading for each institution's rating among these subgroups. Relative proximity and angle between vectors denotes similar factor loadings on the first two principal components.

Figure A.9: Principal Component Analysis of Institutional Confidence, Gallup (2016)

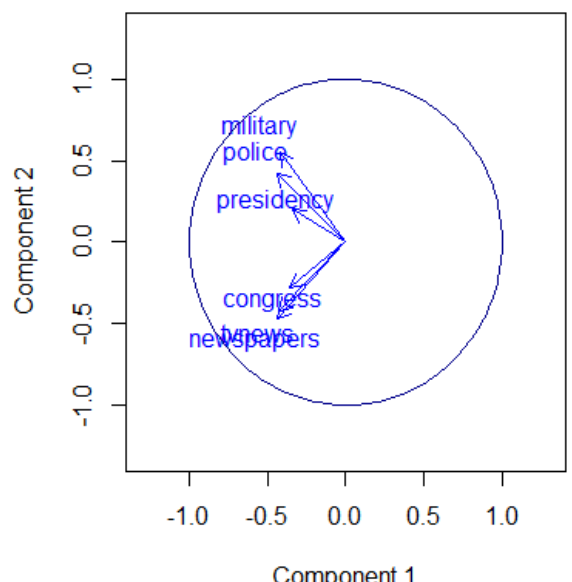

Component 1

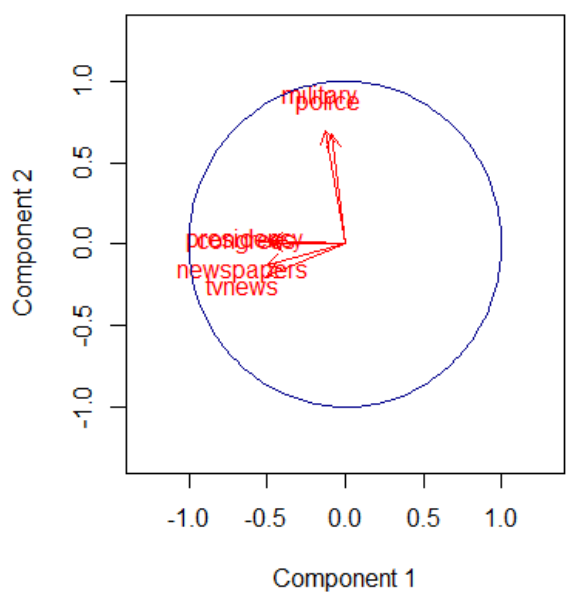

NOTE: Figure A.9 depicts the results of principal component analysis (PCA) on the institutional confidence ratings for several institutions in US society according to the 2016 Gallup poll, broken down by partisan subgroups. First two principal components depicted for clarity. Unit circle denotes maximum value of factor loading for each institution's rating among these subgroups. Relative proximity and angle between vectors denotes similar factor loadings on the first two principal components. 


\section{A.2 Regression-based Analysis for Predictors of High Military Confidence}

Table A.3: Gallup Institutional Confidence Dataset, 1977-2016

\begin{tabular}{|c|c|c|}
\hline & $\begin{array}{c}\text { DV = Binary Confidence } \\
\text { (LPM - Base })\end{array}$ & $\begin{array}{l}\text { ator (Great deal/Quite a lot) } \\
\text { (LPM - Full) }\end{array}$ \\
\hline Republican & $\begin{array}{c}0.136^{* * *} \\
(0.006)\end{array}$ & $\begin{array}{c}0.115^{* * *} \\
(0.006)\end{array}$ \\
\hline Democrat & $\begin{array}{c}0.005 \\
(0.005)\end{array}$ & $\begin{array}{c}0.002 \\
(0.006)\end{array}$ \\
\hline College Educ & & $\begin{array}{c}-0.062^{* * *} \\
(0.005)\end{array}$ \\
\hline Male & & $\begin{array}{c}0.060^{* * *} \\
(0.004)\end{array}$ \\
\hline White & & $\begin{array}{c}0.074^{* * *} \\
(0.007)\end{array}$ \\
\hline GenX Cohort & & $\begin{array}{c}0.001 \\
(0.007)\end{array}$ \\
\hline Millennial Cohort & & $\begin{array}{c}-0.051^{* * *} \\
(0.013)\end{array}$ \\
\hline Silent Cohort & & $\begin{array}{c}0.039^{* * *} \\
(0.005)\end{array}$ \\
\hline Co-Partisan POTUS & & $\begin{array}{c}0.028^{* * *} \\
(0.006)\end{array}$ \\
\hline Constant & $\begin{array}{c}0.546^{* * *} \\
(0.012) \\
\end{array}$ & $\begin{array}{c}0.430^{* * *} \\
(0.014)\end{array}$ \\
\hline Year FE & $\checkmark$ & $\checkmark$ \\
\hline $\mathrm{N}$ & 41,722 & 41,718 \\
\hline $\mathrm{R}^{2}$ & 0.055 & 0.067 \\
\hline Adjusted $\mathrm{R}^{2}$ & 0.054 & 0.066 \\
\hline Residual Std. Error & $0.458(\mathrm{df}=41684)$ & $0.455(\mathrm{df}=41674)$ \\
\hline F Statistic & $65.600^{* * *}(\mathrm{df}=37 ; 41684)$ & $69.739^{* * *}(\mathrm{df}=43 ; 41674)$ \\
\hline
\end{tabular}


Table A.4: General Social Survey (GSS) Dataset, 1973-2016

\begin{tabular}{|c|c|}
\hline & DV = Binary Confidence Indicator (Top 1 of 3 Scale) \\
\hline White & $\begin{array}{c}0.040^{* * *} \\
(0.009)\end{array}$ \\
\hline Republican & $\begin{array}{c}0.134^{* * *} \\
(0.047)\end{array}$ \\
\hline Democrat & $\begin{array}{l}-0.005 \\
(0.047)\end{array}$ \\
\hline Independent & $\begin{array}{l}-0.045 \\
(0.047)\end{array}$ \\
\hline Co-Partisan POTUS & $\begin{array}{c}0.016^{* *} \\
(0.007)\end{array}$ \\
\hline Constant & $\begin{array}{c}2.086^{* * *} \\
(0.050)\end{array}$ \\
\hline Year FE & $\checkmark$ \\
\hline $\mathrm{N}$ & 39,317 \\
\hline $\mathrm{R}^{2}$ & 0.039 \\
\hline Adjusted $\mathrm{R}^{2}$ & 0.038 \\
\hline Residual Std. Error & $0.656(\mathrm{df}=39284)$ \\
\hline F Statistic & $50.088^{* * *}(\mathrm{df}=32 ; 39284)$ \\
\hline
\end{tabular}

${ }^{*} \mathrm{p}<.1 ;{ }^{* *} \mathrm{p}<.05 ;{ }^{* * *} \mathrm{p}<.01$ 
Table A.5: World Values Survey, Wave 5 (2011), US Sample

\begin{tabular}{|c|c|c|c|}
\hline & \multicolumn{3}{|c|}{ DV = Binary Confidence Indicator, Military } \\
\hline & $($ LPM-1) & $(\mathrm{LPM}$-2) & $(\mathrm{LPM}-3)$ \\
\hline Male & $\begin{array}{l}-0.011 \\
(0.016)\end{array}$ & $\begin{array}{c}0.012 \\
(0.015)\end{array}$ & $\begin{array}{c}0.007 \\
(0.015)\end{array}$ \\
\hline College & $\begin{array}{l}-0.002 \\
(0.016)\end{array}$ & $\begin{array}{l}-0.005 \\
(0.016)\end{array}$ & $\begin{array}{l}-0.013 \\
(0.016)\end{array}$ \\
\hline Republican Vote Intent & $\begin{array}{c}0.132^{* * *} \\
(0.020)\end{array}$ & $\begin{array}{c}0.079^{* * *} \\
(0.020)\end{array}$ & $\begin{array}{c}0.067^{* * *} \\
(0.020)\end{array}$ \\
\hline Independent Vote Intent & $\begin{array}{l}-0.016 \\
(0.019)\end{array}$ & $\begin{array}{l}-0.004 \\
(0.018)\end{array}$ & $\begin{array}{c}0.010 \\
(0.018)\end{array}$ \\
\hline Expert_Govt & & $\begin{array}{l}-0.001 \\
(0.015)\end{array}$ & $\begin{array}{c}0.014 \\
(0.016)\end{array}$ \\
\hline Interpersonal Trust & & $\begin{array}{c}-0.076^{* * *} \\
(0.016)\end{array}$ & $\begin{array}{c}-0.058^{* * *} \\
(0.015)\end{array}$ \\
\hline Democracy_Good & & $\begin{array}{c}0.083^{* * * *} \\
(0.020)\end{array}$ & $\begin{array}{c}0.077^{* * *} \\
(0.020)\end{array}$ \\
\hline Defiance Score & & $\begin{array}{c}-0.479^{* * *} \\
(0.045)\end{array}$ & $\begin{array}{c}-0.301^{* * *} \\
(0.057)\end{array}$ \\
\hline Worry_War & & $\begin{array}{c}-0.034^{* * *} \\
(0.011)\end{array}$ & $\begin{array}{c}-0.029^{* *} \\
(0.011)\end{array}$ \\
\hline Worry_Terror & & $\begin{array}{c}0.075^{* * *} \\
(0.012)\end{array}$ & $\begin{array}{c}0.065^{* * *} \\
(0.012)\end{array}$ \\
\hline Worry_Surv & & $\begin{array}{c}-0.036^{* * *} \\
(0.008)\end{array}$ & $\begin{array}{c}-0.029^{* * *} \\
(0.008)\end{array}$ \\
\hline Strong_Ldr & & & $\begin{array}{c}-0.042^{* *} \\
(0.018)\end{array}$ \\
\hline Autonomy Score & & & $\begin{array}{c}0.015^{* *} \\
(0.007)\end{array}$ \\
\hline Disbelief Score & & & $\begin{array}{c}-0.063^{* *} \\
(0.028)\end{array}$ \\
\hline Auth. Score & & & $\begin{array}{c}0.110^{* *} \\
(0.050)\end{array}$ \\
\hline Natl Pride & & & $\begin{array}{c}0.082^{* * *} \\
(0.014)\end{array}$ \\
\hline Science_Faith & & & $\begin{array}{c}-0.006^{*} \\
(0.003)\end{array}$ \\
\hline Constant & $\begin{array}{c}0.813^{* * *} \\
(0.017)\end{array}$ & $\begin{array}{c}0.886^{* * *} \\
(0.040)\end{array}$ & $\begin{array}{c}0.558^{* * *} \\
(0.081)\end{array}$ \\
\hline $\mathrm{N}$ & 2,189 & 2,150 & 2,069 \\
\hline $\mathrm{R}^{2}$ & 0.029 & 0.138 & 0.157 \\
\hline Adjusted $\mathrm{R}^{2}$ & 0.027 & 0.134 & 0.150 \\
\hline Residual Std. Error & $0.365(\mathrm{df}=2184)$ & $0.341(\mathrm{df}=2138)$ & $0.330(\mathrm{df}=2051)$ \\
\hline F Statistic & $16.222^{* * *}(\mathrm{df}=4 ; 2184)$ & $31.231^{* * *}(\mathrm{df}=11 ; 2138)$ & $22.421^{* * *}(\mathrm{df}=17 ; 2051)$ \\
\hline
\end{tabular}

${ }^{*} \mathrm{p}<.1 ;{ }^{* *} \mathrm{p}<.05 ;{ }^{* * *} \mathrm{p}<.01$ 


\section{A.3 Randomization Checks and Covariate Balance}

Table A.6: Randomization Checks and Covariate Balance

\begin{tabular}{ccccc}
\hline \hline Respondent Demographic & Control & Professionalism & Performance & Partisanship \\
\hline $\begin{array}{c}\text { Party Identification } \\
\text { Democrat }\end{array}$ & $37.5 \%$ & $44.1 \%$ & $34.7 \%$ & $35.7 \%$ \\
Republican & $20.8 \%$ & $21.4 \%$ & $22.1 \%$ & $28.4 \%$ \\
Gender & & & & \\
Male & $44.1 \%$ & $46.1 \%$ & $40.0 \%$ & $46.3 \%$ \\
Female & $60.0 \%$ & $54.0 \%$ & $60.1 \%$ & $53.6 \%$ \\
Age & & & & \\
25th Percentile & 37 & 35.75 & 29 & 33 \\
50th Percentile & 50 & 47 & 46 & 60 \\
75th Percentile & 62 & 61 & 61 & \\
Race & & & & \\
White & $69.0 \%$ & $67.5 \%$ & $71.1 \%$ & $34.5 \%$ \\
Non-white & $31.0 \%$ & $32.4 \%$ & $28.8 \%$ & 246 \\
\hline \hline Sample Size & 245 & 256 & 253 & \\
\hline \hline
\end{tabular}

NOTE: Percentages reflect segment of survey population assigned to each experimental condition broken down by key demographic values. Subjects were assigned on a random basis to each of the four conditions. 
Table A.7: Randomization Check: Logit Regression with Treatment Assignment as DV

\begin{tabular}{lcccc}
\hline \hline & \multicolumn{3}{c}{ Dependent variable: } & Treatment Assignment \\
\cline { 2 - 5 } & Control & Partisan & Professional & Performance \\
& $(1)$ & $(2)$ & $(3)$ & $(4)$ \\
\hline Democrat & -0.069 & -0.206 & 0.232 & 0.037 \\
& $(0.174)$ & $(0.171)$ & $(0.171)$ & $(0.173)$ \\
Independent & 0.212 & $-0.365^{*}$ & -0.038 & 0.174 \\
& $(0.207)$ & $(0.215)$ & $(0.215)$ & $(0.207)$ \\
Male & -0.024 & 0.132 & 0.125 & -0.236 \\
& $(0.150)$ & $(0.149)$ & $(0.147)$ & $(0.149)$ \\
Age & 0.007 & -0.002 & 0.001 & -0.005 \\
& $(0.004)$ & $(0.004)$ & $(0.004)$ & $(0.004)$ \\
White & 0.002 & -0.227 & -0.024 & 0.250 \\
& $(0.165)$ & $(0.162)$ & $(0.161)$ & $(0.165)$ \\
Constant & $-1.459^{* * *}$ & $-0.757^{* * *}$ & $-1.241^{* * *}$ & $-0.958^{* * *}$ \\
& $(0.290)$ & $(0.285)$ & $(0.286)$ & $(0.284)$ \\
\hline Observations & 1,000 & 1,000 & 1,000 & 1,000 \\
Log Likelihood & -554.703 & -555.304 & -567.054 & -562.331 \\
Akaike Inf. Crit. & $1,121.407$ & $1,122.608$ & $1,146.109$ & $1,136.662$ \\
\hline \hline
\end{tabular}

NOTE: $\dagger p<0.10,{ }^{*} p<0.05,{ }^{* *} p<0.01,{ }^{* * *} p<0.001$. 


\section{B Appendix B: Media Reporting Supporting Results}

\section{B.1 Supplementary Wartime Reporting Statistics}

Table B.1: Descriptive Statistics, Iraq War Reporting: Cable News (2007)

\begin{tabular}{lcccc}
\hline \hline & \multicolumn{4}{c}{ Mean Percentage of Sampled Newshole } \\
\cline { 2 - 5 } News Source & PBS & CNN & MSNBC & FOX News \\
\hline Combat Events & 9.18 & 6.12 & 6.85 & 3.62 \\
& $(<0.001)$ & $(<0.001)$ & $(<0.001)$ & \\
Domestic/Homefront & 27.12 & 6.57 & 10.75 & 4.62 \\
& $(<0.001)$ & $(0.07)$ & $(0.01)$ & \\
Policy Debate & 26.38 & 13.03 & 25.28 & 9.97 \\
& $(<0.001)$ & $(0.01)$ & $(<0.001)$ & \\
\hline Observations & 431 & 468 & 243 & 394 \\
\hline \hline
\end{tabular}

NOTE: Reported figures depict average percent of daily newshole dedicated to segments on Iraq War stories across the entire 2007 news year. Values in parentheses () indicate p-values for two-tailed t-test for difference in means between reported news source and FOX News as reference category. 
Figure B.1: Media Coverage of Military News Stories by Source, 2007

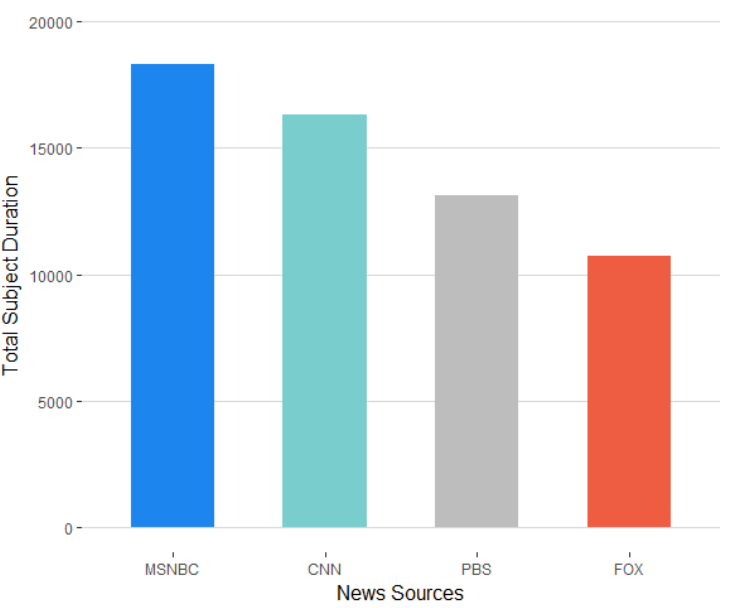

(a) "2007 Troop Increase" Coverage

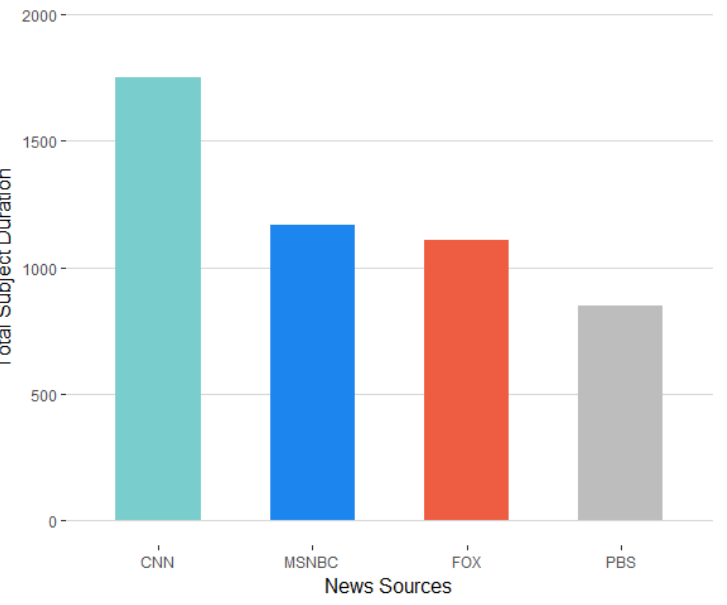

(c) "Pat Tillman Scandal" Coverage

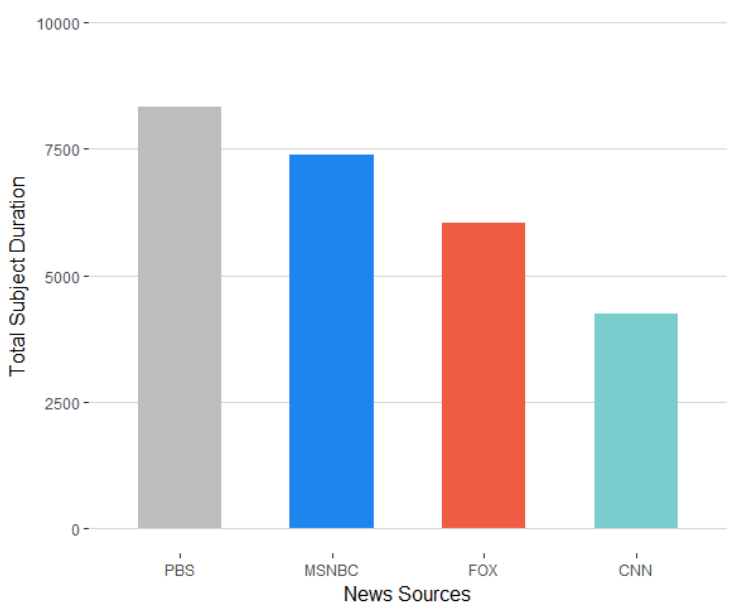

(b) "Petraeus Report to Congress" Coverage

$$
1500-
$$

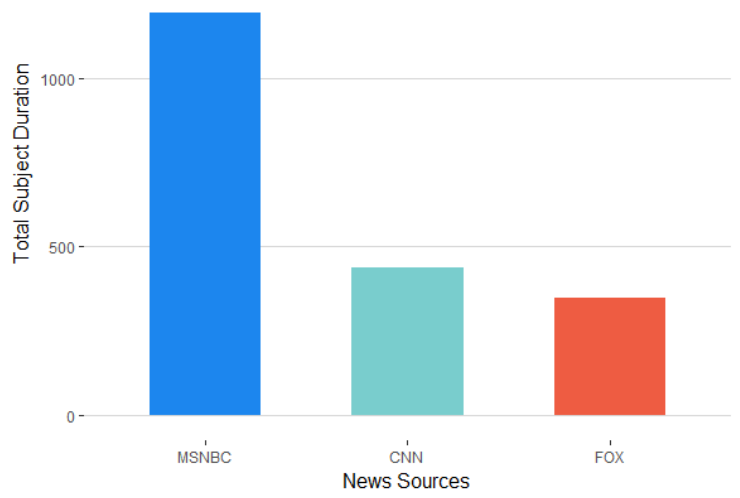

(d) "Comparisons to Vietnam" Coverage

NOTE: These figures display the total duration (in on-air seconds) devoted by each of the major television news sources to each of the indicated sub-storylines as coded and sampled by the 2007 Pew Research News Content Index (NCI) dataset. Total source broadcast time calculated by summing total on-air time spent on each sub-storyline across all segments in each source. 

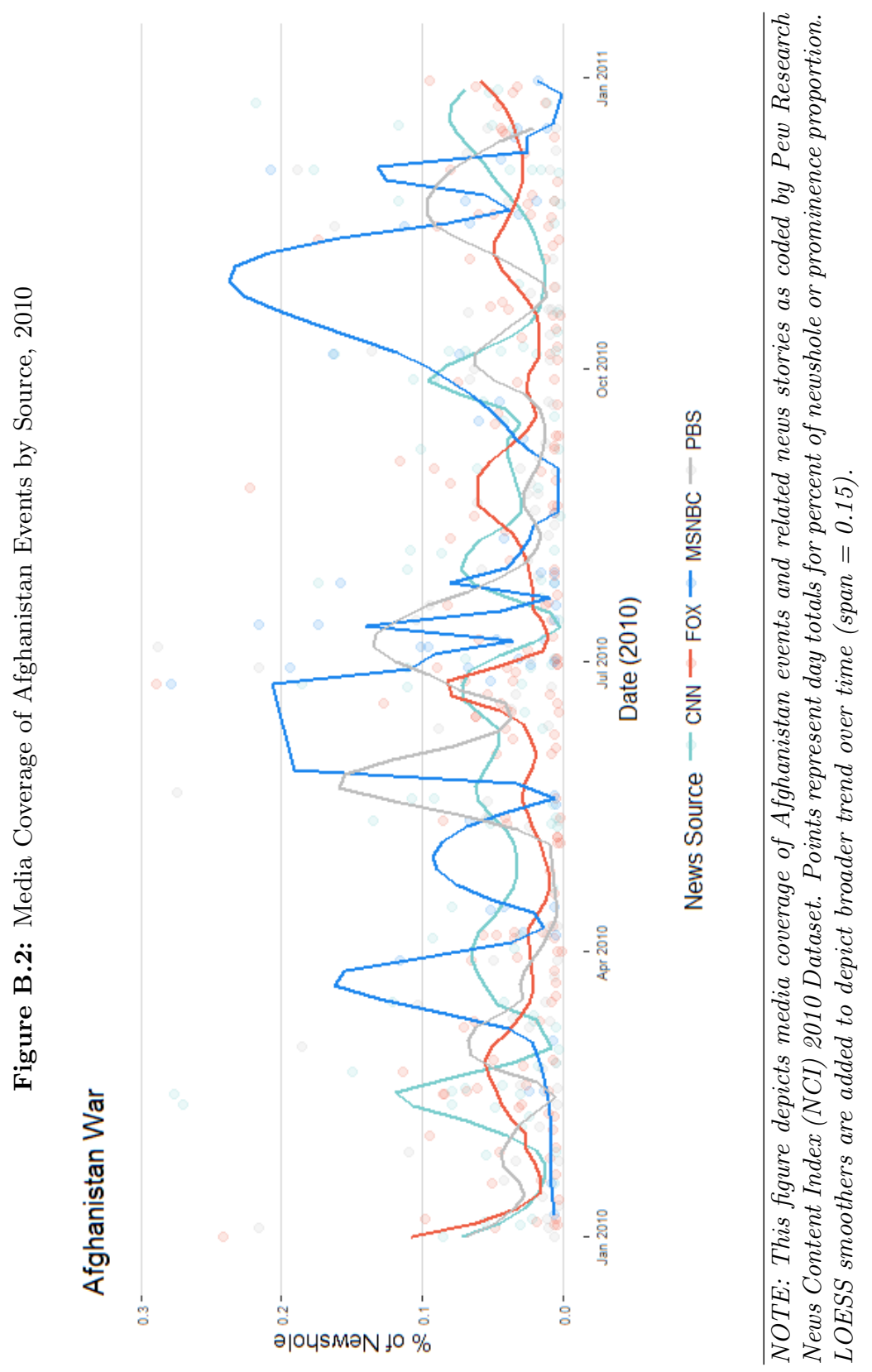


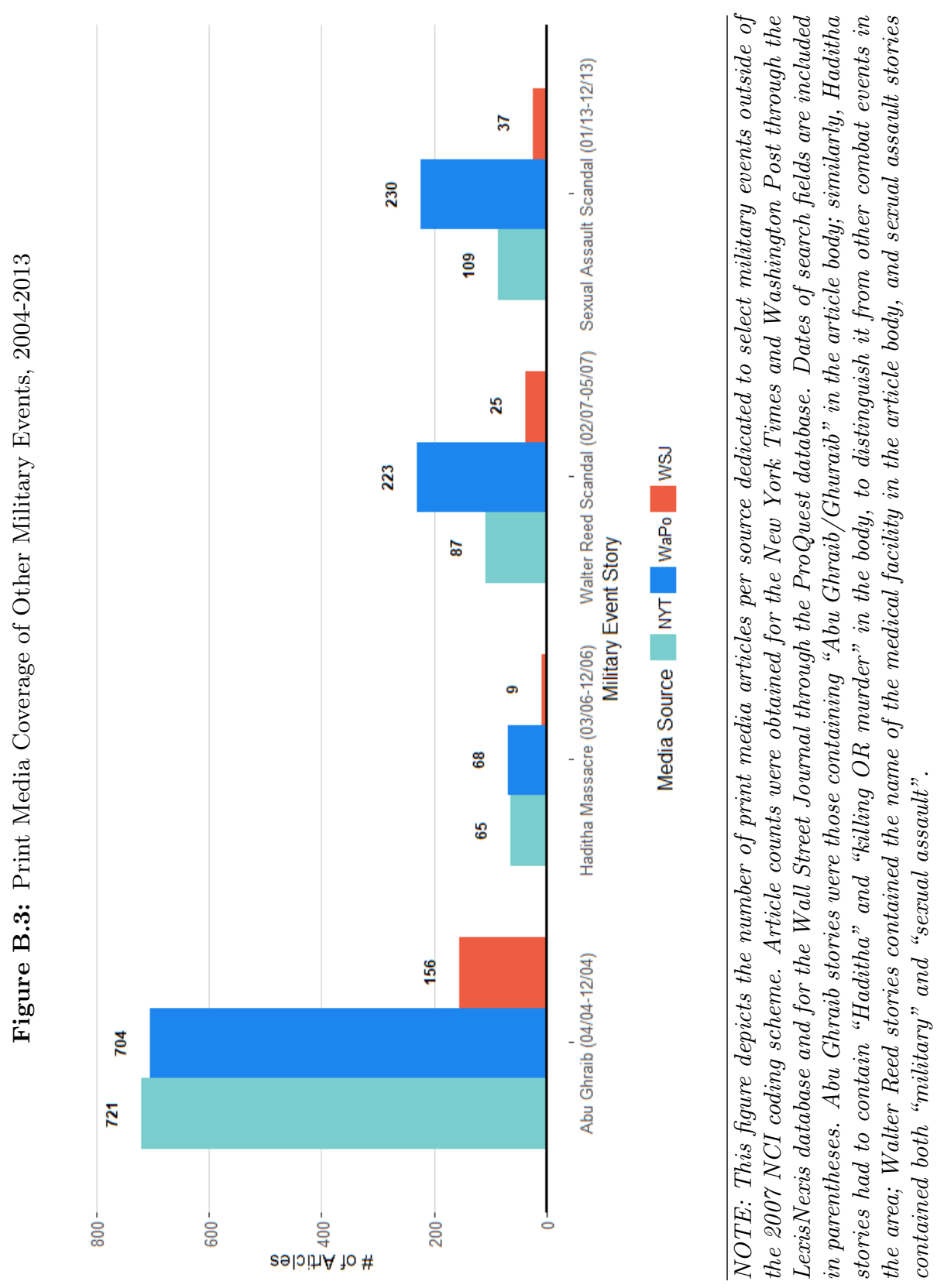




\section{B.2 Topic Model Articles}




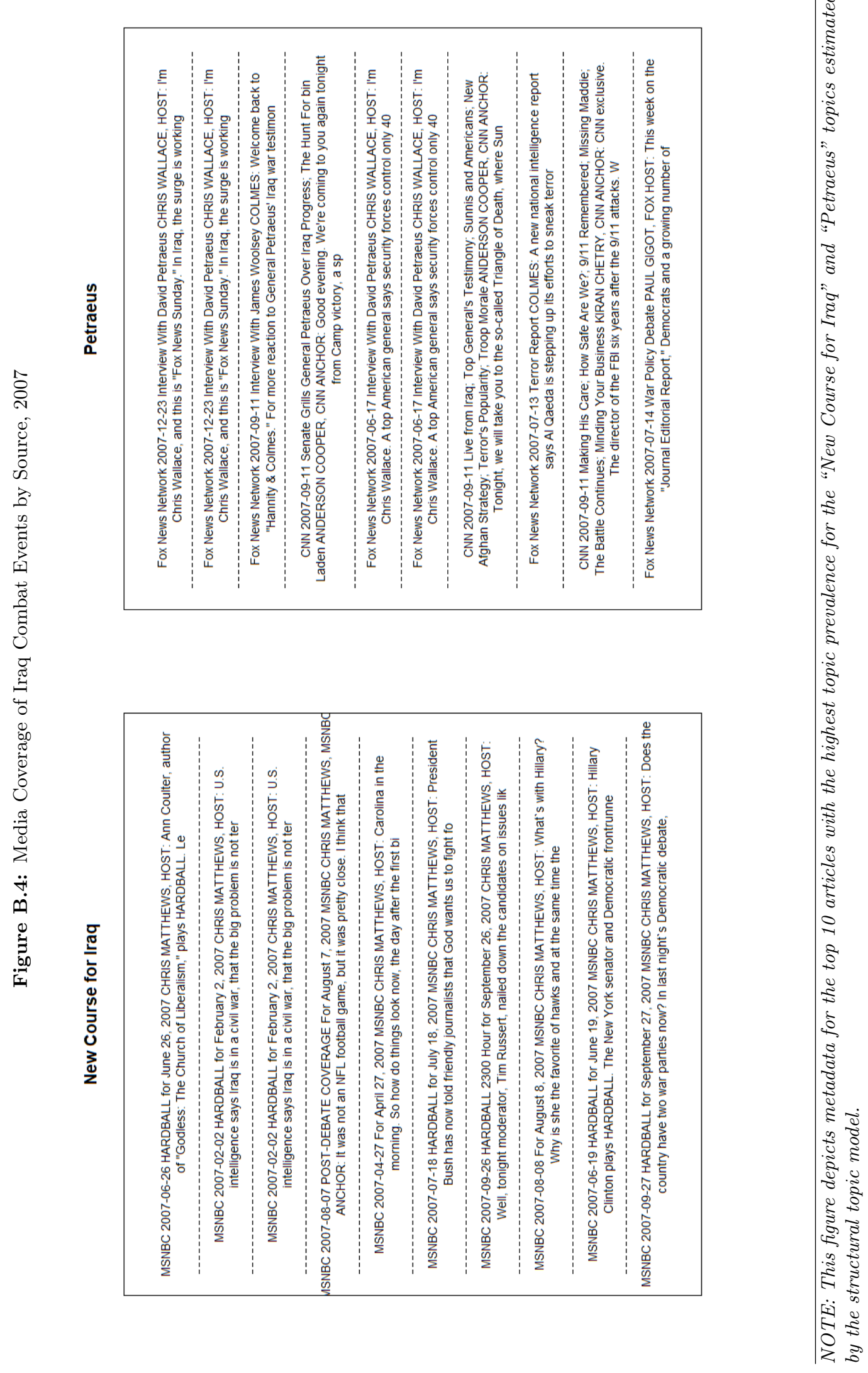




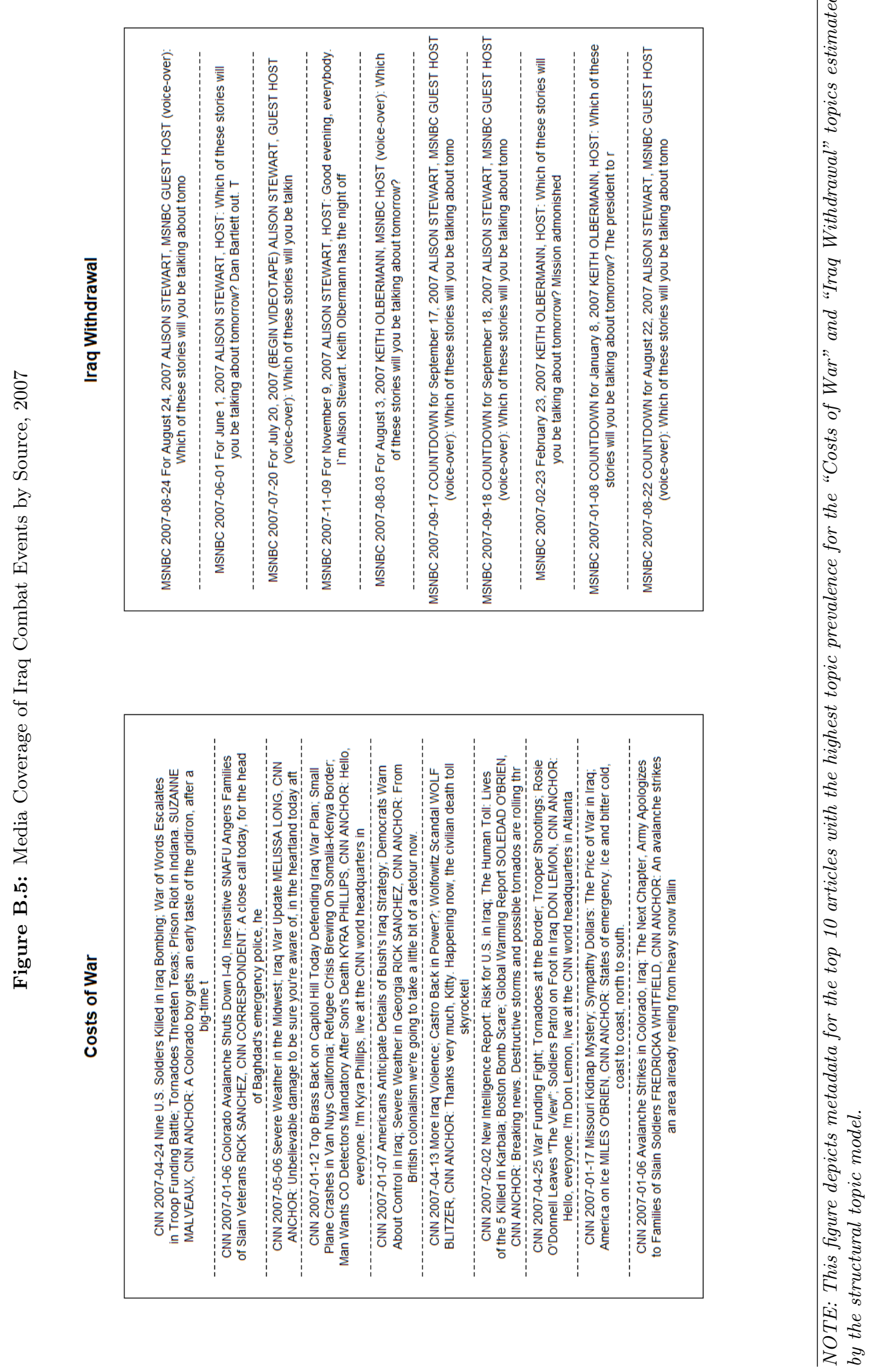




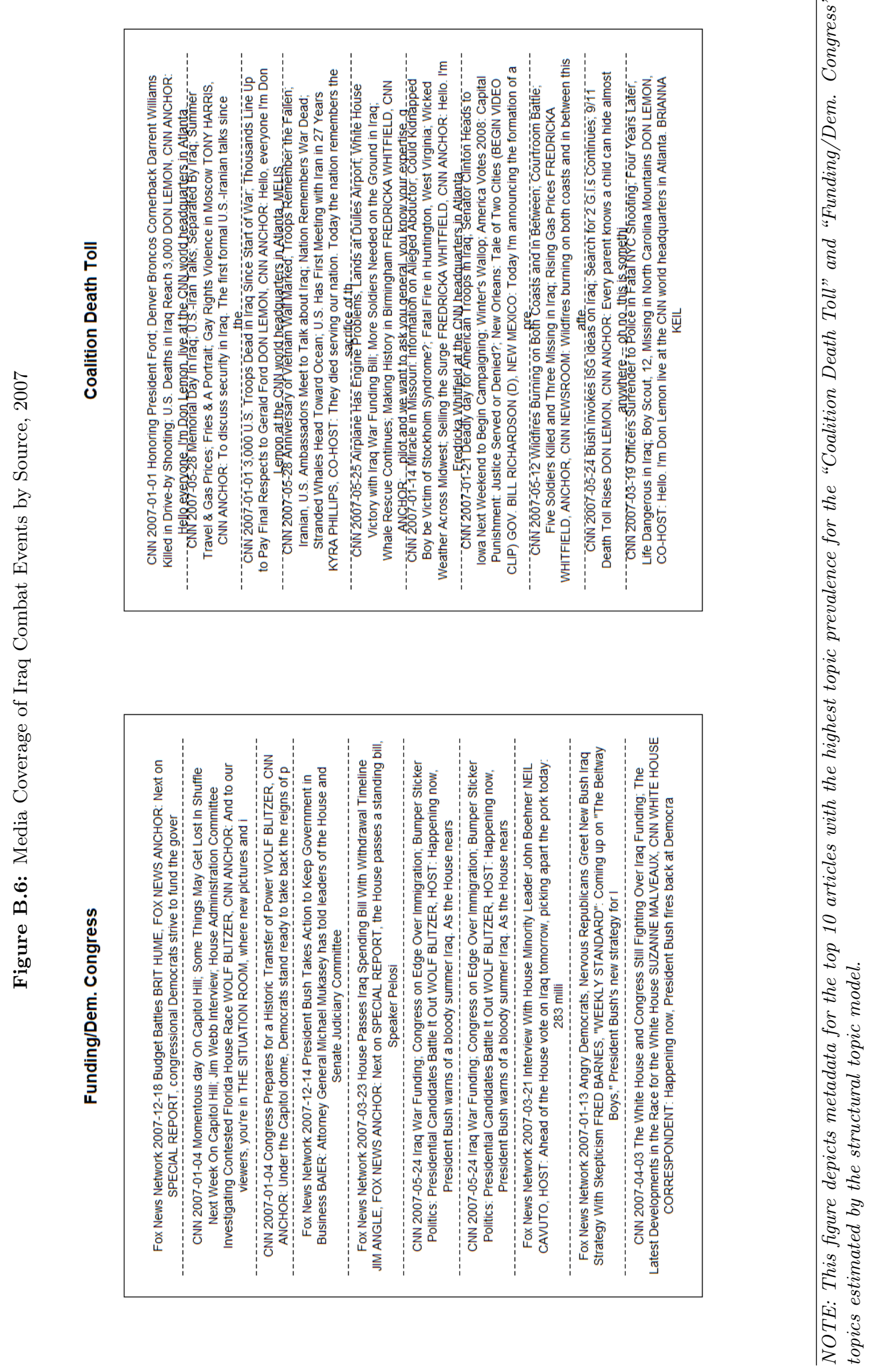




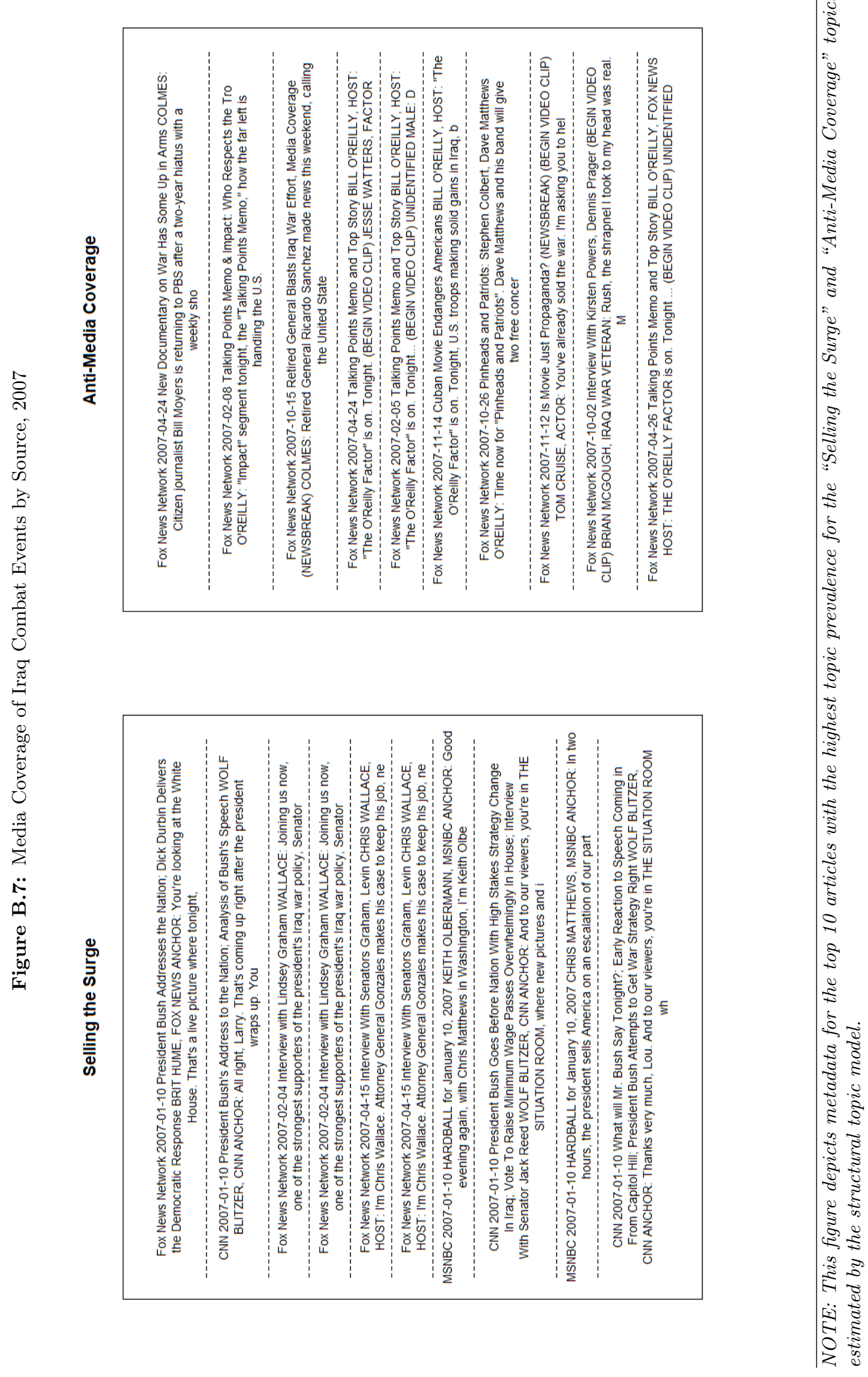




\section{B.3 Supplementary Experimental Results}




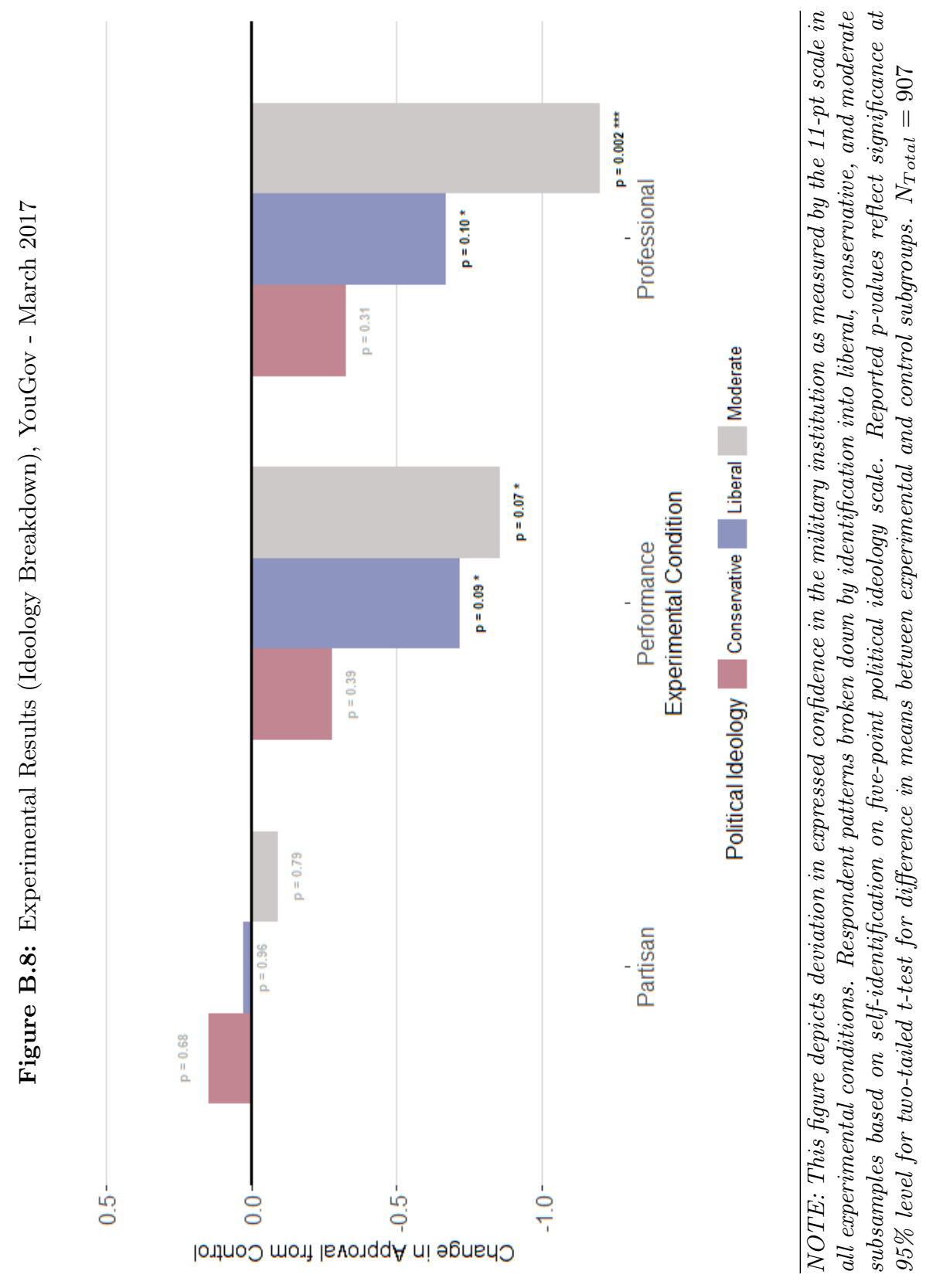




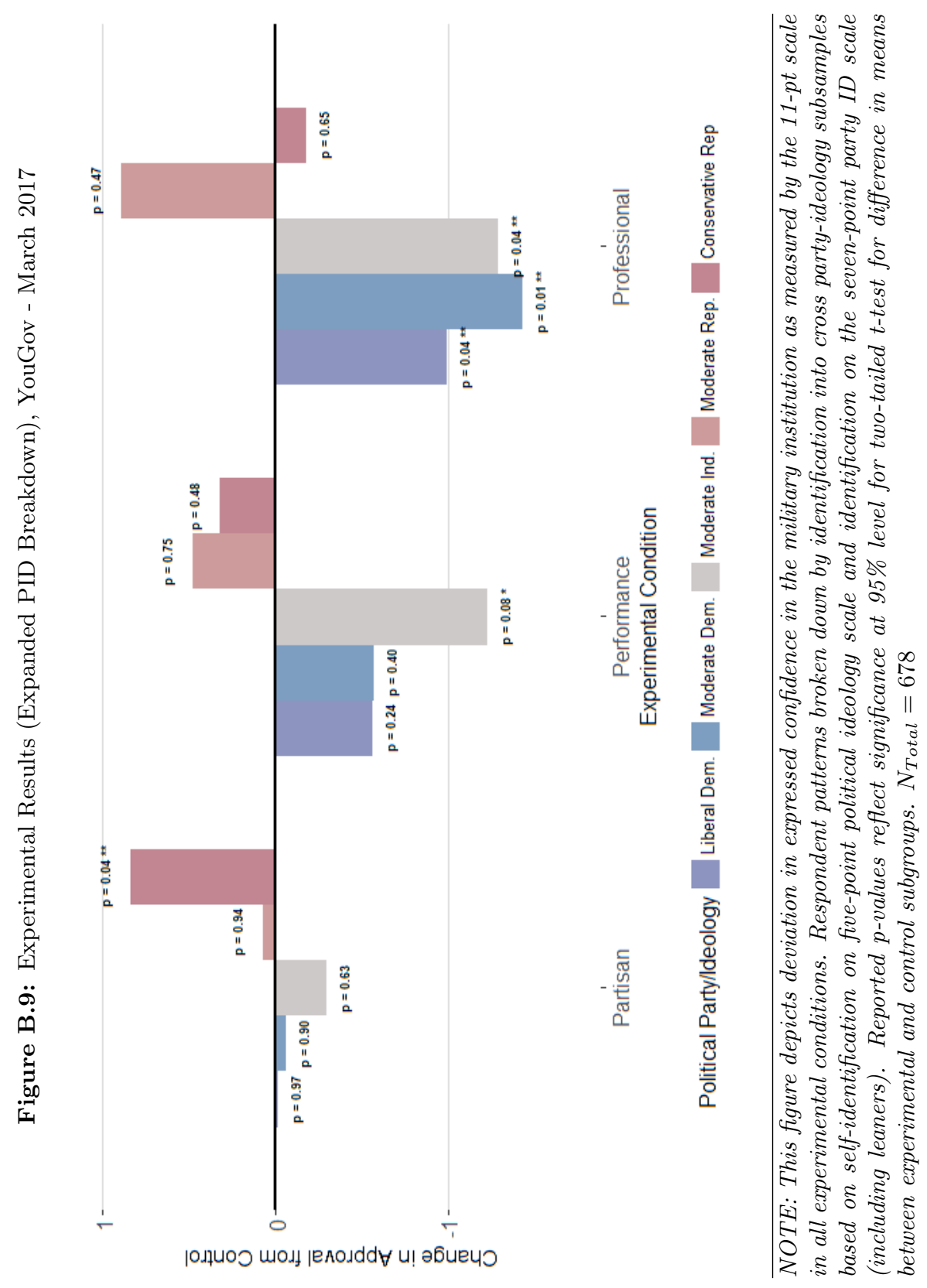




\section{Appendix C: Pew Research News Content Index (NCI) Dataset}

\section{C.1 Dataset Methodology}

Analysis of the selective exposure hypotheses conducted in the main body of the text draw extensively on media reporting data provided by the Pew Research News Content Index (NCI) Dataset, a samplingbased index of stories reported by major media outlets across television, the internet, radio, and print newspapers. A full description of the dataset's methodology can be found on the Pew Research website $^{34}$ However, for the purposes of this analysis, I provide an overview of the collection and coding schemes for the NCI dataset, as the selective exposure argument uses this data in 2007 to make the case for limited reporting across conservative outlets on Iraq Combat Events.

The population of data points captured by the dataset's sampling process produces an image of the media information environment per day, meant to be "illustrative but not strictly representative". This is to say that the dataset employs quasi-random sampling of news stories across the different media, weighting these observations based on the number of outlets per medium, the number of programs per outlet, and the volume of news to be collected during given periods of time. Coding the entire content of a news segment or newspaper is prohibitively time consuming. As a result, the collection process increases efficiency at the cost of completeness by focusing on the most prominent aspects of these segments, such as using the first 30-minutes of television news segments or the front page of print media sources in order to provide an accurate picture of the predominant stories during a given news cycle. While this means the image captured by the dataset is a sampled subset of prominent stories, this does not pose a serious threat to inference in the selective exposure argument discussed in the main body of the text. Lead stories and newspaper headlines are precisely the high-salience, high-exposure stories that this hypothesis is attempting to test for distribution and acceptance by the public; as a result, "D-block" television segments or non-front page, under-the-fold print stories are less important to our consideration.

\footnotetext{
${ }^{34}$ Pew Research Center Journalism and Media, News Content Index Methodology http://www.journalism.org/news_ index_methodology accessed October 18, 2017.
} 


\section{Network Television News}

The network television news medium includes morning and evening segments broadcast by the three major networks (ABC, CBS, and NBC) and the evening segments of PBS. The three primary networks typically air two daytime programs (such as the Today Show or Good Morning America) and one evening program, whereas PBS is typically captured in a sampling of Newshour with Jim Lehrer. Collection of story topics for these programs codes the substance of the first 30 minutes of one or two of the three programs, which typically focus on stories of national importance. Though this means that stories at the end of the broadcast are less likely to be collected, Pew Research asserts that "we have learned that the morning shows generally move away from the news of the day after the first 30 minutes". Evening news segments are collected in a similar fashion, with the entire 30 minutes of two of the three programs a day being sampled. Finally, the PBS Newshour broadcast rotates to be coded based on the first 30 minutes, followed by the second 30 minutes, followed by its non-collection.

All television programs, both network and cable news, are coded based on the entire 30 minutes time frame of collection, discounting inserts from local affiliates, advertisements, promotions, or weather reports. Furthermore, segments within a programs will be coded in their entirety even if they run past the 30 minute time window (for instance, a three-minute segment that started at the 28 -minute mark would be coded even though it concludes at the 31-minute mark). Removing local inserts, non-substantive information, and "teasers" of upcoming stories narrows the collected sample to the top stories of national importance. Therefore, despite the rotating sample scheme, the information collected is representative of the prevailing news stories of the day.

\section{Cable Television News}

Cable news focuses on particular sources in a similar fashion, utilizing the top three cable news distributors by audience reach (MSNBC, CNN, and FOX). Selection on these subsets precluded the inclusion of corporately-related by unsampled news source like CNBC, or CNN Headline News. Because cable news broadcasts on a continuous basis, a different scheme of collection is adopted due to the indistinguishability of segments from the same network to a broad audience. Instead, Pew breaks the reporting day into four time periods: early morning, daytime, early evening, and primetime. Early morning segments are not collected due to the fact that they are not uniformly available to a national audience; east coast 
segments are broadcast too early for west coast audience to consume. Daytime segments are collected in a manner similar to network news, with two 30 minute segments collected per day, rotating among the three networks.

Early evening and primetime, taken together, form a news block typically lasting from 6PM to 11PM on weekdays. Prior to 2009, CNN and FOX had three of their four cable news programs coded, with MSNBC having two of their four coded. This was done is reflection of the audience reach at the time, in which MSNBC had lower ratings than CNN and FOX. Since 2009, this has been amended to sample one or two segments from CNN, one or two segments from MSNBC, and two segments from FOX, for a total of between 30-60 minutes of coded substance per source per day, for a total of nearly 3.5 hours of coded substance per day.

Figure C.1: Pew Research NCI Dataset, Cable News Sampling Scheme Post-2011

Below is the current list of evening cable programs included in our sample as of August 2011.

\begin{tabular}{|c|c|c|c|}
\hline & CNN & Fox News & MSNBC \\
\hline $6 \mathrm{p} . \mathrm{m}$ & Situation Room & Special Report w/Bret Baier & \\
\hline $7 \mathrm{p} . \mathrm{m}$ & John King, USA & $\begin{array}{r}\text { Fox Report w/ Shephard } \\
\text { Smith }\end{array}$ & Hardball \\
\hline 8 p.m. & Anderson Cooper 360 & The O'Reilly Factor & The Last Word \\
\hline 9 p.m. & - & Hannity & The Rachel Maddow Show \\
\hline 10 p.m. & - & - & The Ed Show \\
\hline
\end{tabular}

NOTE: This figure depicts the post-2011 collection scheme for cable news segments during the critical early evening-primetime joint period. This is an amendment from the collection scheme used for the main body's data from 2007 in that while CNN and FOX would have had three of their programs sampled, MSNBC would only have had two sampled. Figure created by Pew Research available at http: //www. journalism. org/news_index_methodology.

For our purposes, the sampling scheme for collection of the news story data warrants several considerations. First, the rotating basis of the collection during the relevant time period of analysis (2007) means that liberal news source MSNBC would have had far fewer opportunities to be collected; as a result, the gap in reporting trends between conservative and liberal media outlets on Iraq Combat Events may actually be biased downward since more MSNBC stories were not collected to this end. FOX and CNN would have been, on average, collected $50 \%$ more than the MSNBC segments; while this is reflec- 
tive of differing audience reach, it also heightens the importance of reporting biases between sources as discussed in the main analysis. Second, the rotation scheme does not harm inference based on $\%$ of newshole' dependent variable use. The graphically displayed reporting trends in Figure 3 utilize daily percentages of the Iraq Combat Event-related segments as a percentage of the collected outlet airtime. Because of the rotating collection scheme as it was conducted pre-2011, this means that day-to-day total time per outlet would have remained fixed, while segment length devoted to this story, our main variable of interest, was allowed to vary based on news source. These daily percentages were then plotted as individual pointed that the LOESS smoother could visually depict in a more substantively useful fashion.

\section{Newspapers}

Analysis of print media relied on collection of same-day delivery of electronic, full-text versions of the major newspapers through various providers available to Pew Research. The newspapers are organized on a three-tiered system of audience reach and level of distribution. As of 2007, when the substantive data used in the main analysis was collected, Tier 1 included The New York Times, Wall Street Journal, LA Times, USA Today, and The Washington Post, though the latter has since fallen to Tier 2 due to lower circulation. Tier 2 newspapers typically include regionalized print media with local audiences and non-national distribution, such as the Atlanta Constitution-Journal, while Tier 3 are more localized. Collection on a daily basis included coding two of the four Tier 1 papers per day. Since no Tier 2 or Tier 3 papers enter in our analysis, I leave discussion of that analysis scheme out.

Again, complete coding of the entire newspaper is cost prohibitive for minimal quantitative value. Two of the four Tier 1 papers are sampled each day, with the sampled newspapers being coded based on the stories which appear on page A1, both above and below the fold, and any substance continued inside the newspaper so long as it begins on the front page. The logic for consideration of these stories is that editors make a conscious choice to allocate finite column-inches to stories of particular import. Just as non-collection of local inserts or the last 30 minutes of network news increases efficiency with little loss of substance, so too does ignoring inside-the-fold stories that were not prominent or important enough to be placed on the front page. The purpose of the index, and its application for this study, is the frequency and location of specific story topics in the information environment; as such, study of headlines and lead stories is precisely where focus ought to be. This scheme results in about 20 newspaper stories collected and coded per day. 
For this analysis, newspaper prominence was calculated using the NCI's five-point scale of story prominence, inverting the scale, and dividing the selected story by the sum of all stories from that paper per day. For example, a story about Iraq Combat Events featured on the front page of The New York Times that was coded as "Front Page/Second Prominent", would have been entered as 102 in the dataset, on the scale of 101 (Front Page/Most Prominent) to 105 (Front Page/Other, Below the Fold). I repurpose this measure into an inverse five-point scale of importance; the above story would be given a score of 4, just as a story that was 104: Front Page/Other, Above the Fold would have been given a 2. I sum the total prominence of stories reported by that source as divide it by the prominence of the observed story, in order to ascertain a proxy measure of the percentage of finite prominence the editor's devoted to the story. As argued here, this is a fair measure of the importance of the story to this source and its availability to its audience.

\section{Radio}

Because online news sources do not factor in my analysis, I also forgo discussion of their collection scheme. Radio sources, however, factor prominently in my analysis as a decidedly conservative-heavy transmission medium for information. Because of the wide variation in types of radio sources, Pew subsets the available radio outlets into one of three categories. First, Public Radio collects rotating 30-minute segments of National Public Radio's (NPR) Morning Edition and All Things Considered. The scheme of sampling rotates between the first 30 minutes of the former, the second 30 minutes of the former, the first 30 minutes of the latter, and the second 30 minutes of the latter. NPR broadcasts are typically two hours in length for either segment, with member stations picking which parts of that broadcast to incorporate into their own. The dataset includes additional 30-minute sampling of WFYI, the member station from which Pew collects NPR broadcasts.

The second category, Talk Radio, includes those outlets with a public affairs of news-oriented tone. Just as larger conservative audiences on cable news leads to a sampling scheme that favors FOX over MSNBC, the vastly larger conservative audience for talk radio favors Hannity and Rush Limbaugh over Ed Schultz; as of 2007, Schultz and Hannity were sampled every other day and Limbaugh was sampled everyday, with all coded based on the first 30 minutes of the broadcast. Again, this upweights the conservative outlets measured in the 2007 version of the dataset, with conservative media outlets collected 
more frequently in line with their larger audience reach. The third category is Headline Feeds, which are hourly news feeds from larger national outlets like CBS or CNN, but are of limited length and typically sum up national or international headlines from the parent news source. Pew NCI collects two Headline Feeds per day, at ABC and CBS Radio, each for five minutes in length for a total of 10 minutes per day.

This analysis calculated the length of the segment spent of specific topics (like Iraq Combat Events) as a percentage of the total length of the segment. Again, the total length of the recorded segment is fixed while the time spent on specific subjects is allowed to vary. One key consideration for this analysis is the large oversampling of conservative radio outlets compared to only five-minute headline feeds from more centrist or liberal news sources. In any given day, Hannity or Limbaugh have nearly 5-10 times more airtime to discuss high-salience news stories than the headline feeds. This imbalance biases the expected result of our analysis downward, making the gap in reporting trends even more stark. With less time to report on specific stories, headline feeds still spend more time talking about war events than conservative radio hosts, as seen in Figure 3. 


\section{Appendix D: Survey Experiment Supplementals}

\section{D.1 Questionnaire Design}

Programming Instructions: Assign random integer from 1 to 4, record this integer as assignment. Assignment of this integer is recorded and dictates the value of [Prompt1],[Prompt2], and [Text].

\section{Assigning Textual Prompt}

The variable [Text] takes on the following values depending on integer assignment:

- Assignment $=1,[$ Text $]=$ We are interested in how well certain news stories regarding US foreign policy can reach the public. The length of the 'war on terror' and associated US military activities have created a large amount of information that can be hard to follow.

- Assignment $=2,3,4,[$ Text $]=$ We are interested in how well certain news stories regarding US foreign policy can reach the public. The length of the 'war on terror' and associated US military activities have created a large amount of information that can be hard to follow. We want to ask about some stories that occurred and were reported to see if you happened to hear about them.

\section{Assigning News Vignette \#1}

The variable [Prompt1] takes on the following values depending on integer assignment:

- Assignment=1, [Prompt1] = Would you say that you follow stories about US foreign policy in the news?

- Assignment=2, [Prompt1] =Story 1: The 2012 presidential election saw candidates Barack Obama and Mitt Romney receive many high-profile endorsements, several hundred of which coming from the military community. Among these were retired military officers General Wesley Clark, former Supreme Allied Commander in Europe, and General Tommy Franks, former commander of US forces in the Middle East, who publicly supported Obama and Romney, respectively.

- Assignment=3, [Prompt1]=Story 1: In 2009, several former Army soldiers received multiple life sentences for an event in 2006 where the men had participated in the rape and murder of a 14-year old Iraqi girl. The soldiers, stationed near the town of Mahmudiyah at the time, were convicted of this crime along with the murder of the girl's mother, father, and younger sister.

- Assignment=4, [Prompt1] =Story 1: A British development aid worker named Linda Norgrove was captured by Taliban forces in eastern Afghanistan in late 2010. During an attempted raid to free the captured civilian, members of the Navy's SEAL Team Six accidentally killed Norgrove when one of the sailors mistakenly threw a grenade into the area where she was hiding. 


\section{Assigning News Vignette \#2}

The variable [Prompt2] takes on the following values depending on integer assignment:

- Assignment $=1,[$ Prompt2] $=$ Would you say that you follow stories about US military operations in the news?

- Assignment=2, [Prompt2]=Story 2: During the 2016 presidential campaign, both presidential candidates announced broad support from retired military officers like General Mike Flynn and General John Allen, who supported Trump and Clinton, respectively. Donald Trump released a list of 88 retired generals and admirals that publicly supported his candidacy, while Hillary Clinton released a similar list of 110 retired generals and admirals that supported her campaign.

- Assignment=3, [Prompt2]=Story 2: In the last few years, the military has experienced problems with misconduct by high-ranking officers, prompting the resignation of figures like former General David Petraeus, for example. A report commissioned by the Defense Department in 2012 found that nearly thirty generals and admirals had been investigated for offenses ranging from sexual assault, misuse of government funds, gambling scandals, and inappropriate statements about members of Congress.

- Assignment=4, [Prompt2]=Story 2: In October 2015, US and Afghan forces fighting in the city of Kunduz struggled to remove Taliban elements from the town. During the fight, US combat aircraft misidentified a nearby medical facility staffed by Médecins sans Frontières (Doctors Without Borders) and destroyed the hospital, killing more than 30 aid workers and wounding many more. A follow-up investigation attributed the accident to "human error" by US service members. 


\section{Survey Progression}

Standard demographic battery precedes the experimental portion of the survey.

\section{[TEXT]}

\section{[PROMPT1]}

Question 1: SINGLE CHOICE. Interest/Knowledge

- Control Group (Assignment=1) Foreign Policy Interest

- Treatment Groups (Assignment=2,3,4) News Knowledge 1

Did you hear this story?

- Yes/No

\section{[PROMPT2]}

Question 2: SINGLE CHOICE. Interest/Knowledge

- Control Group (Assignment=1) Foreign Policy Interest

- Treatment Groups (Assignment=2,3,4) News Knowledge 2

Did you hear this story?

- Yes/No

Question 3-5: DYNAMIC GRID. Institutional Confidence

On scale of 0-10 (with 0 being the least and 10 being the most), how much trust and confidence do you have in each of the following institutions?

Rows [randomized order]

- Congress

- The presidency

- The military 


\section{D.2 News Vignette Analogs}

Each of the treatment conditions in this experimental design was exposed to news stories that were intended to provoke "top-of-the-head" thinking and introduce specific types of newly-salient information regarding military misconduct of poor performance. In order to minimize deception and increase external validity, the stories used were actual cases of partisan, professional, and performance-based events reported in multiple news outlets. Below, I provide a short summary of each of the cases used for vignettes in this experiment and the relevant cites for these stories in the information environment.

\section{Partisan Activity}

The first partisan vignette included information about retired military elites, including General Wesley Clark and General Tommy Franks, providing high-profile endorsements to presidential candidate Mitt Romney and President Barack Obama in the 2012 presidential campaign. Clark, a retired Supreme Allied Commander of NATO Force Europe and former 2004 Democratic presidential candidate, was one of several prominent military officers to endorse the incumbent president; along with retired Major General Paul Eaton, these officers opposed Mitt Romney's take on foreign policy early in the campaign season and touted Obama's successful operation to kill Osama bin Laden ${ }^{35}$ Obama's campaign co-chairs included retired Admiral John Nathman, the former second-highest ranking officer in the Navy, who would go on to speak at the Democratic National Convention. ${ }^{36}$ The endorsements for Mitt Romney were considerably more numerous; on the eve of the election, nearly 500 retired generals and admirals sponsored a full-page ad in the Washington Times endorsing Romney. The list involved five former Chairmen of the Joints Chiefs of Staff - including Clinton appointee General Hugh Shelton and General Tommy Franks, the former Central Command (CENTCOM) commander in 2003 during the Iraq invasion under President Bush. ${ }^{37}$

In the second vignette, similar information is exposed to the respondent regarding endorsement in the 2016 president campaign, though in this election both candidates displayed both high-profile individual endorsements and large blocs of retired officers. Republican nominee Donald Trump released a letter in September 2016 with the endorsement of 88 retired generals and admirals, including former

\footnotetext{
${ }^{35}$ Nia-Malika Henderson, "Gen. Wes Clark set to pound Romney on foreign policy", The Washington Post, November 21, 2011

${ }^{36}$ Byron Tau, "Obama campaign announces co-chairs", Politico44 Blog, February 22, 2012

${ }^{37}$ Stephan Dinan, "Retired top military brass push for Romney", The Washington Times, November 4, 2012.
} 
commander of US forces in Korea General Burwell Bell and former commander of the US Army's Delta Force, Lieutenant General Jerry Boykin. Trump's list boasted officers who were more advanced in age and had retired ten or more years previously, though most notable among his military endorsements was that of retired Lieutenant General Mike Flynn, a close adviser and former intelligence officer who would go on to speak at the Republican National Convention ${ }^{38}$ Democratic nominee Secretary Hillary Clinton responded with her own list of 110 retired officers' endorsements, including recent Afghanistan forces commander General John Allen and General Wesley Clark once again. Allen would go on to speak at the party nominating convention that year as well, with Clark leading a cadre of 15 officers who independently voiced their fears over a Trump presidency and the denigration of fellow veteran Senator John McCain that Trump has stated earlier. ${ }^{39}$

\section{Professionalism Failures}

In the second treatment condition, individuals were exposed instead to priming information regarding professional or ethical failures by military elites or the institution as a means for making such calculations salient to the respondent's calculation of confidence in the military. The intent in this treatment condition was to focus on events of singular or collective values violations in which the driving mechanism was not incompetence, but rather motivated harm or ethical faults. In the first vignette, respondents were exposed to a news story regarding the trial and conviction of several US soldiers in 2009 for an event which occurred in Mahmudiyah, Iraq in 2006. A group of five soldiers led by Private Steven Dale Green, raped a 14-year old Iraqi girl before proceeding to kill both her and her family. Green's unit was serving in the famed Sunni "Triangle of Death" outside of Baghdad when the incident occurred, followed by his arrest and the arrest of four other soldiers who participated in the crime. The event was all the more damaging to the military's institutional reputation as Green had been arrested shortly before his enlistment, admitted to the Army on one of the many "moral waivers" the military had issued in an attempt to boost recruitment in the worst years of the Iraq war. ${ }^{40}$

In the second vignette, respondents were exposed to a news story that focused on the elite-level of

\footnotetext{
${ }^{38}$ David Wright, Ryan Browne, and Naomi Lin, "88 former military leaders write letter backing Donald Trump for president", CNN, September 6, 2016.

${ }^{39}$ Dianna Cahn, "Former admirals and generals warn Trump is 'dangerous' to military and country", Stars and Stripes, September 21, 2016; Dan Merica, "Clinton to Trump: My military endorsements are bigger than yours", CNN, September 9, 2016.

${ }^{40}$ Jim Dwyer and Robert F. Worth, "Accused G.I. Was Troubled Long Before Iraq", The New York Times, July 14, 2006 .
} 
the military institution and its misconduct. This involved the 2014 publication of the increasingly list of senior military officials relived of command or fired due to various forms of misconduct and professional failures. Citing the 2012 resignation of retired General David Petraeus from his post as Director of Central Intelligence due to an unknown affair as the impetus, Defense Secretary Leon Panetta commissioned a study of ethical standards for senior officers. Resulting media exposure captured misconduct ranging from sexual assault, sexual misconduct, forgery, public intoxication, bribery, unauthorized gift acceptance from foreign entities, and misuse of government funds. ${ }^{41}$ In many cases, the hypocrisy of the violations was particularly egregious, from a South Carolina-based one-star general advocated "zerotolerance for sexual harassment" while being investigated for assaulting his mistress, to the relief of a high-ranking nuclear commander for public drunkenness while with Russian military officials in Moscow.

\section{Battlefield Performance Problems}

In the third treatment condition, respondents were subjected to news stories regarding military failures of a standard variety: battlefield results. This included cases of incompetence, miscalculation, miscoordination, or tactical lack of proficiency designed to make salient the standard calculation of confidence in the military institution according the institutionalist theory. The first vignette detailed the failure of a 2010 mission by the Navy's SEAL Team Six to rescue Linda Norgrove, a British national and aid worker captured by elements of the Taliban. Norgrove was moved outside the compound in which the SEALs believed she was housed by her captors and one of the team's members accidentally killed Norgrove with a grenade believing her to be an enemy combatant. ${ }^{42}$ In addition to drawing attention to a tactical failure by the military institution, it also invokes the popularly-recognized SEAL Team Six, made famous from successful operations in anti-piracy off the coast of Somalia in 2009 and in Pakistan to killed Osama bin Laden in 2011. Using such an organization is meant to draw a stronger contrast in the miscalculation between expectation and newly-salient information.

In the second vignette, respondents were exposed to a story detailing the accidental bombing of a Medecins sans Frontieres (Doctors without Borders) clinic in Kunduz, Afghanistan, in 2015. The clinic's staff were administering to the increasing number of wounded created by Taliban resurgence in Kunduz.

\footnotetext{
${ }^{41}$ Craig Whitlock, "Military brass, behaving badly: Files detail a spate of misconduct dogging armed forces", The Washington Post, January 26, 2014.

${ }_{42}$ Anthony Faiola, "British aid worker Norgrove killed accidentally bu U.S. soldier, inquiry finds", Washington Post Foreign Service, December 3, 2010
} 
Part of coalition response to the increased violence included fire from a nearby AC-130 Spectre gunship, which despite initial reports was called in to support US efforts on the ground. In the subsequent investigation, it was clear that the location of the hospital was in dispute at numerous points, resulting in a nearly 30-minute barrage on the clinic that left 42 dead and dozens more wounded. President Obama apologized directly to the president of MSF, admitting US miscalculations in the incident. ${ }^{43}$ In this case, miscalculations of targeting and tactical proficiency not only failed to produce a positive outcomes, but created a tangibly negative one in the destruction of a medical facility crewed largely by third-party nationals.

\footnotetext{
43 "Obama apologises to MSF president for Kunduz bombing", BBC News, October 7, 2015. Obama's apology was also given amidst increasing rumors that the attack was a deliberate move by the US to dislodge Taliban fighters "holed up" in the clinic, though this was eventually denied by both the US and MSF.
} 